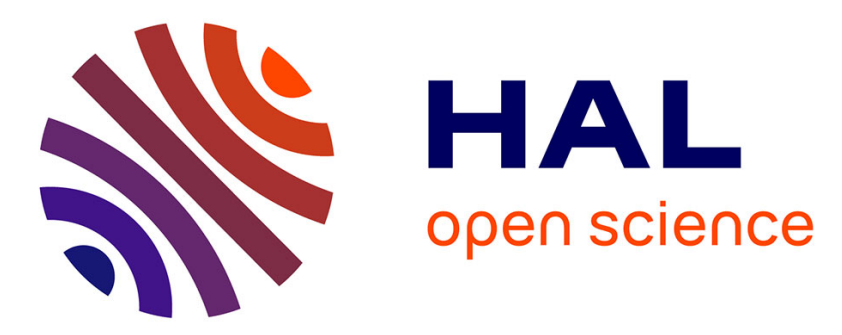

\title{
Edgeworth and Lindahl-Foley equilibria of a general equilibrium model with private provision of pure public goods
}

\author{
Monique Florenzano, Elena L. del Mercato
}

\section{- To cite this version:}

Monique Florenzano, Elena L. del Mercato. Edgeworth and Lindahl-Foley equilibria of a general equilibrium model with private provision of pure public goods. Journal of Public Economic Theory, 2006, 8 (5), pp.713-740. 10.1111/j.1467-9779.2006.00285.x . halshs-00085726

\section{HAL Id: halshs-00085726 \\ https://shs.hal.science/halshs-00085726}

Submitted on 13 Jul 2006

HAL is a multi-disciplinary open access archive for the deposit and dissemination of scientific research documents, whether they are published or not. The documents may come from teaching and research institutions in France or abroad, or from public or private research centers.
L'archive ouverte pluridisciplinaire HAL, est destinée au dépôt et à la diffusion de documents scientifiques de niveau recherche, publiés ou non, émanant des établissements d'enseignement et de recherche français ou étrangers, des laboratoires publics ou privés. 


\title{
EDGEWORTH AND LINDAHL-FOLEY EQUILIBRIA OF A GENERAL EQUILIBRIUM MODEL WITH PRIVATE PROVISION OF PURE PUBLIC GOODS
}

\author{
MONIQUE FLORENZANO \\ CNRS-CERMSEM, MSE Université Paris 1 \\ ELENA L. del MERCATO \\ Università degli Studi di Salerno
}

\begin{abstract}
In this paper, we propose a definition of Edgeworth equilibrium for a private ownership production economy with (possibly infinitely) many private goods and a finite number of pure public goods. We show that Edgeworth equilibria exist whatever be the dimension of the private goods space and can be decentralized, in the finite and infinite dimensional cases, as Lindahl-Foley equilibria. Existence theorems for Lindahl-Foley equilibria are a by-product of our results.
\end{abstract}

\section{INTRODUCTION}

In this paper, we consider a private ownership production economy with (possibly infinitely) many private goods and a finite number of pure public goods. Finitely many households have an initial endowment of private goods and jointly consume private goods and a same amount of public goods; this amount of public goods is jointly produced with private goods by finitely many competitive firms.

In such a model, financing the production of public goods can be thought of in two different ways. Either, following Villanacci and Zenginobuz (2001), households are supposed to make voluntary purchases (or privately provide amounts) of public goods, determining the total provision of public goods entering in the utility function of each household. The economic meaning of this approach is justified by the existence of private donations to charity and many other examples where a public good is provided in a market without government involvement. Or, in a Lindahlian approach, households are allowed to pay for the total amount of public goods a personalized price, the sum of personalized prices determining the public good vector price used by the competitive firms. As long as no equilibrium concept is defined, both formalizations are obviously equivalent. In counterpart, two different equilibrium concepts can be defined which differ by the optimization problem solved

Monique Florenzano, CNRS-CERMSEM, MSE Université Paris 1, 106-112 Boulevard de l'Hôpital, 75647 Paris Cedex 13, France (monique.florenzano@univ-paris1.fr). Elena L. del Mercato, Dipartimento di Scienze Economiche e Statistiche, Università degli Studi di Salerno, Via Ponte don Melillo, I-84084 Fisciano (Salerno), Italy (edmercat@unisa.it).

This version of the paper was prepared during reciprocal visits of E. L. del Mercato to CERMSEM and of M. Florenzano to DIMAD, University of Florence. The hospitality of both institutions is gratefully acknowledged. It has benefitted from discussions with the members of these research centers. Presented at a seminar of the Department of Economics of the University of Naples, at the 13th European Workshop on General Equilibrium Theory in Venice (2004), at the PET04 Conference in Peking (2004), it has also benefitted from the comments of these audiences. Special thanks go to N. Allouch and V. Iehlé for remarks on previous drafts of this paper. 
by households at equilibrium. In the classical line of general equilibrium with preferences depending on the consumption of the other consumers, households may be assumed to take their own provision decision taking as given not only the market prices but also the provision decisions of the other households. Then prices, individual consumptions of private goods and individual provisions of public goods arise from the competitive functioning of the productive system and the market clearing. This is the equilibrium concept studied by Villanacci and Zenginobuz (2001, 2003). Such an equilibrium can easily be shown to be constrained optimal (for an optimality notion where the choices of each household are constrained by the choices of the other households). It has no reason to be Pareto optimal, for the optimality notion commonly adopted in a public good framework and that we use in this paper. On the other hand, in the line of Foley (1970), households may be assumed to consume private goods and to claim an amount of public goods taking as given the private good prices and their personalized vector of public good prices. Then, personalized prices and the equilibrium allocation arise from the competitive functioning of the productive system and the market clearing. As shown by Foley in the case of a convex and constant returns technology, such an equilibrium is optimal for the optimality notion corresponding to the public good framework, and belongs to the core of the economy.

Coherent with this definition of optimality, the main result of this paper is the definition and existence of Edgeworth equilibria for our economy. Since prices are not involved in optimality, core and limit-core concepts, we adapt the classical definitions to the public good model in the Villanacci-Zenginobuz framework that we set in Section 2. This adaptation, done in Section 3, is not trivial. In particular, the definition of blocking for coalitions of replica economies requires some caution. It is known (see for example Conley 1994) that if blocking is defined in replica economies as it is defined for coalitions of the original economy, then the core of a public goods economy may not converge as the economy gets large. Our concept of blocking in replica economies is justified by the consideration of the aspects of crowding and congestion. The idea is that for most of public goods, the appreciation we have is dependent on the "size" of the group of consumers of the same type in the coalition (see Section 4 of Milleron 1972 who suggests the idea, see Section 2 of Vasil'ev 1994-96, and Vasil'ev, Weber and Wiesmeth 1995 who focus on the equivalence theorem). Non-emptiness of the core and, with the definition of blocking we propose for replica economies, existence of Edgeworth equilibria for a convex economy with private provision of public goods are shown in Section 4 under some classical assumptions on the model. Since we work with utility functions, we prove the non-emptiness of the core using Scarf's theorem (actually, an extension of Scarf's theorem). The existence of Edgeworth equilibria is classically proved using compactness arguments.

We then look for decentralization with prices of an Edgeworth equilibrium allocation so as to get at least a quasiequilibrium of the model. It appears that the equilibrium concept adapted to our concept of Edgeworth equilibrium is that of Lindahl-Foley equilibrium that we precisely define in Section 5. As known since Foley (1970) and Milleron (1972), this equilibrium can be seen as the equilibrium of an economy with only private goods defined on an enlarged commodity space. We follow this strategy and study the correspondence between optimality, core and limit-core concepts in the economy with public goods and the usual corresponding concepts in the enlarged economy. Decentralization in the public good economy is then driven by known results of decentralization in the enlarged economy. This decentralization is studied first in a finite dimensional setting. Existence theorems for Lindahl-Foley equilibrium are a by-product of our two results of existence of Edgeworth equilibria and of their decentralization as Lindahl-Foley equilibria. Equivalence and existence theorems for Lindahl-Foley equilibria are obtained under weaker assumptions than in the 
literature. When, in order to model time and uncertainty, the private commodity space is assumed to be infinite dimensional, the same results involve structural assumptions on the commodity-price duality of the model and properness assumptions borrowed from Tourky $(1998,1999)$.

To end, it is worth noticing that our results strongly rely on the convexity assumptions made in particular on the production of public goods. The private production of public goods, and the related convexity assumptions, distinguish our model from a different approach to the pure theory of public goods, initiated by Mas-Colell (1980) and studied by Mas-Colell and Silvestre (1989), Weber and Wiesmeth (1991), Diamantaras and Gilles (1996), De Simone and Graziano (2004), where aside a convex private ownership economy there is a set (with or without linear structure) of public projects each one characterized by a cost in terms of private goods. These authors develop a notion of valuation equilibrium in which the public project is financed through a nonlinear system of personalized prices called valuation system, and they show the first and second welfare theorems. As pointed out by Mas-Colell (1980), when the set of public projects has a linear structure and the valuation system is restricted to be linear homogeneous, then the concept of a valuation equilibrium coincides with the concept of (valuation) Lindahl equilibrium. Moreover, with only one private good, as shown by Mas-Colell and Silvestre (1989), a Lindahl-Foley equilibrium is a particular case of valuation equilibrium (called linear cost share equilibrium). If in addition, the cost function is convex, proving the existence of Edgeworth equilibria that we decentralize as Lindahl-Foley equilibria, we go further than these authors. But the main interest of their approach is precisely to deal with the nonlinear and nonconvex cases.

\section{THE MODEL}

We consider a production economy with a (possibly infinite dimensional) private commodity space $L$ and private provisions of a finite number $K$ of public goods

$$
\mathcal{E}=\left(\left\langle L \times \mathbb{R}^{K}, L^{\prime} \times \mathbb{R}^{K}\right\rangle,\left(X_{h}, u_{h}, e_{h}\right)_{h \in H},\left(Y_{f}\right)_{f \in F},\left(\theta_{h, f}\right)_{\substack{h \in H \\ f \in F}}\right) .
$$

- $\left\langle L, L^{\prime}\right\rangle$ is a pair of vector spaces and an associated bilinear functional $\langle\cdot, \cdot\rangle$ that separates points, so that $\left\langle L \times \mathbb{R}^{K}, L^{\prime} \times \mathbb{R}^{K}\right\rangle$ represents the commodity-price duality of the model. As usual, we will denote by $\left(p, p^{g}\right) \cdot\left(z, z^{g}\right)=p \cdot z+p^{g} \cdot z^{g}$ the evaluation of $\left(z, z^{g}\right) \in L \times \mathbb{R}^{K}$ at prices $\left(p, p^{g}\right) \in L^{\prime} \times \mathbb{R}^{K}$. We assume moreover that $L$ is a partially ordered vector space, while $\mathbb{R}^{K}$ is canonically ordered. In the case of a finite number of private goods, $L$ is some Euclidean space $\mathbb{R}^{C}$, which will be equipped with its canonical topology, and $L^{\prime}$ is identified with $\mathbb{R}^{C}$.

- There is a finite set $H$ of households. Each household $h$ has the positive cone $X_{h}=L_{+} \times \mathbb{R}_{+}^{K}$ of the commodity space as choice set and an initial endowment $e_{h}=\left(\omega_{h}, 0\right) \in L_{+} \times\{0\}$, that is, no initial endowment in public goods. For a generic element $\left(x_{h}, x_{h}^{g}\right) \in L_{+} \times \mathbb{R}_{+}^{K}$ of $h$ 's choice set, $x_{h} \in L_{+}$is the private commodity consumption of household $h$, while the components of the vector $x_{h}^{g} \in \mathbb{R}_{+}^{K}$ denote the amount of each public good that household $h$ provides. Household $h$ 's preferences depend on the provision of public goods of the other agents and are represented by a utility function $u_{h}: L_{+} \times \mathbb{R}_{+}^{K} \rightarrow \mathbb{R}$,

$$
\left(x_{h}, \sum_{h^{\prime} \in H} x_{h^{\prime}}^{g}\right) \rightarrow u_{h}\left(x_{h}, \sum_{h^{\prime} \in H} x_{h^{\prime}}^{g}\right)
$$

defined over his consumption of private goods and the total provision of public goods $G=$ $\sum_{h^{\prime} \in H} x_{h^{\prime}}^{g}$. 
- There is a finite set $F$ of firms which jointly produce private and public goods. Each firm is characterized by a production set $Y_{f} \subset L \times \mathbb{R}_{+}^{K}$. We denote by $\left(y_{f}, y_{f}^{g}\right)$ a generic point of $Y_{f} . Y=\sum_{f \in F} Y_{f}$ denotes the total production set.

- For every firm $f$ and each household $h$, the firm shares $0 \leq \theta_{h, f} \leq 1$ classically represent a contractual claim of household $h$ on the profit of firm $f$ when it faces a price $\left(p, p^{g}\right) \in$ $L^{\prime} \times \mathbb{R}^{K}$. In a core and Edgeworth equilibrium approach, the relative shares $\theta_{h, f}$ reflect household's stock holdings which represent proprietorships of production possibilities and $\theta_{h, f} Y_{f}$ is interpreted as a technology set at $h$ 's disposal in $Y_{f}$. As usual, $\sum_{h \in H} \theta_{h, f}=1$, for each $f$.

Let $\omega$ denote the total endowment of private goods, that is, $\sum_{h \in H} e_{h}=(\omega, 0)$. An allocation is a t-uple $\left(\left(x_{h}, x_{h}^{g}\right)_{h \in H},\left(y_{f}, y_{f}^{g}\right)_{f \in F}\right) \in\left(L_{+} \times \mathbb{R}_{+}^{K}\right)^{H} \times \prod_{f \in F} Y_{f}$. By abuse of language, we speak of $\left(x_{h}, x_{h}^{g}\right)_{h \in H}$ as a consumption allocation when we should speak of a consumers' choice allocation. The allocation $\left(\left(x_{h}, x_{h}^{g}\right)_{h \in H},\left(y_{f}, y_{f}^{g}\right)_{f \in F}\right)$ is feasible if

$$
\sum_{h \in H}\left(x_{h}, x_{h}^{g}\right)=(\omega, 0)+\sum_{f \in F}\left(y_{f}, y_{f}^{g}\right) .
$$

As usual, $\mathcal{A}(\mathcal{E})$ denotes the set of feasible allocations. Using the appropriate projections of this set on $\left(L_{+} \times \mathbb{R}_{+}^{K}\right)^{H}$, on each copy $X_{h}$ of $L_{+} \times \mathbb{R}_{+}^{K}$ and on each $Y_{f}$, let $\widehat{X}, \widehat{X}_{h}$ for each $h \in H$, $\widehat{Y}_{f}$ for each $f \in F$, respectively denote the set of feasible consumption allocations, and the feasible choice sets for each household and each firm. Let $\sigma$ be a topology on $L$ non necessarily compatible with the duality $\left\langle L, L^{\prime}\right\rangle$ and let $\tau_{\mathbb{R}^{K}}$ denote the canonical topology on $\mathbb{R}^{K}$. We will maintain in the whole paper the following set of minimal assumptions on the economy $\mathcal{E}$ called in the sequel standard assumptions:

A1: For each $h \in H$,

- $X_{h}=L_{+} \times \mathbb{R}_{+}^{K}$, and $e_{h}=\left(\omega_{h}, 0\right) \in L_{+} \times \mathbb{R}_{+}^{K}$,

- $u_{h}$ is quasi-concave and monotone with respect to public goods, that is, for every $x_{h} \in L_{+}, G^{\prime} \geq G$ implies $u_{h}\left(x_{h}, G^{\prime}\right) \geq u_{h}\left(x_{h}, G\right)$,

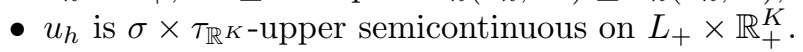

A2: For each $f \in F$,

- $Y_{f} \subset L \times \mathbb{R}_{+}^{K}$ is convex and $0 \in Y_{f}$,

- If $\left(y_{f}, y_{f}^{g}\right) \in Y_{f}$, then $\left(y_{f}, 0\right) \in Y_{f}$.

A3: The set $\widehat{X}$ is $\left(\sigma \times \tau_{\mathbb{R}^{K}}\right)^{H}$-compact.

In A1, the first assumption on each $X_{h}$ and $e_{h}$ is constitutive of the model. Monotonicity of utilities with respect to public goods ("No public bads") will play a decisive role in our proofs. In A2, the first assumption on each $Y_{f}$ is constitutive of the model. Free disposal of public goods is assumed in the second part of A2. If the dual pair $\left\langle L, L^{\prime}\right\rangle$ is a symmetric Riesz dual system ${ }^{1}$ and if $\sigma$ is the weak topology $\sigma\left(L, L^{\prime}\right)$ associated with the duality $\left\langle L, L^{\prime}\right\rangle$, then Assumption $\mathbf{A} \mathbf{3}$ is implied by the assumption that $(Y+(\omega, 0)) \cap\left(L_{+} \times \mathbb{R}^{K}\right)$ is $\sigma\left(L, L^{\prime}\right) \times \tau_{\mathbb{R}^{K} \text {-compact. This is proved }}$ in Proposition 4.1 of Aliprantis, Brown and Burkinshaw (1987) for a private ownership economy and easily adapted to our model of public good economy.

\footnotetext{
${ }^{1}$ That is $\left\langle L, L^{\prime}\right\rangle$ is a dual pair of Riesz spaces and the order intervals of $L$ are $\sigma\left(L, L^{\prime}\right)$-compact.
} 


\section{Optimality, CORE AND Limit-CORE CONCEPTS}

The purpose of this section is to give a series of definitions that adapt to the previous model the standard optimality, core and limit-core concepts usually defined for a private ownership production economy with only private goods.

Definition 3.1. A feasible consumption allocation $\left(\bar{x}_{h}, \bar{x}_{h}^{g}\right)_{h \in H} \in \widehat{X}$ is said to be weakly Pareto optimal if there is no other feasible consumption allocation $\left(x_{h}, x_{h}^{g}\right)_{h \in H} \in \widehat{X}$ such that

$$
u_{h}\left(x_{h}, \sum_{h^{\prime} \in H} x_{h^{\prime}}^{g}\right)>u_{h}\left(\bar{x}_{h}, \sum_{h^{\prime} \in H} \bar{x}_{h^{\prime}}^{g}\right) \text { for each } h \in H .
$$

Definition 3.2. Let $S \subset H, S \neq \varnothing$ be a coalition.

(1) $\left(x_{h}, x_{h}^{g}\right)_{h \in S} \in \prod_{h \in S} X_{h}$ is a feasible choice assignment for the coalition $S$ if

$$
\sum_{h \in S}\left(x_{h}, x_{h}^{g}\right) \in\left\{\sum_{h \in S} e_{h}\right\}+\sum_{h \in S f \in F} \sum_{h f} \theta_{f}
$$

(2) The coalition $S$ improves upon or blocks a feasible consumption allocation $\left(\bar{x}_{h}, \bar{x}_{h}^{g}\right)_{h \in H}$ in $\widehat{X}$ if there exists a feasible choice assignment $\left(x_{h}, x_{h}^{g}\right)_{h \in S} \in \prod_{h \in S} X_{h}$ for the coalition $S$ such that

$$
u_{h}\left(x_{h}, \sum_{h^{\prime} \in S} x_{h^{\prime}}^{g}\right)>u_{h}\left(\bar{x}_{h}, \sum_{h^{\prime} \in H} \bar{x}_{h^{\prime}}^{g}\right) \text { for each } h \in S .
$$

Let $\bar{G}=\sum_{h \in H} \bar{x}_{h}^{g}$ and $G^{S}=\sum_{h \in S} x_{h}^{g} . \bar{G}$ and $G^{S}$ can be thought of as the respective amounts of public goods entering as arguments in the utility function of each member of the coalition $S$ depending on his non-participation or his participation in the coalition. Thus, an interpretation of the previous definition is the following: a coalition $S$ blocks the feasible pair $\left(\left(\bar{x}_{h}\right)_{h \in H}, \bar{G}\right)$ if its members can consume some amount of private goods $\left(x_{h}\right)_{h \in S}$ and claim some amount of public goods $G^{S}$ that they unanimously prefer and can afford using their own resources. We will alternatively say that the coalition $S$ blocks or improves upon the feasible pair $\left(\left(\bar{x}_{h}\right)_{h \in H}, \bar{G}\right)$ with the $S$-feasible pair $\left(\left(x_{h}\right)_{h \in S}, G^{S}\right)$.

Definition 3.3. The core $\mathcal{C}(\mathcal{E})$ of the economy $\mathcal{E}$ is defined as the set of all feasible consumption allocations (alternatively, the set of all feasible pairs) of $\mathcal{E}$ that no coalition can improve upon.

We now continue with the replication concepts adapted to our model.

Definition 3.4. Let $n$ be any positive integer. The $n$-fold replica of $\mathcal{E}$ is an economy composed of $n$ subeconomies identical to the original one

$$
\mathcal{E}_{n}=\left(\left\langle L \times \mathbb{R}^{K}, L^{\prime} \times \mathbb{R}^{K}\right\rangle,\left(u_{h, s}, e_{h, s}\right) \underset{\substack{h \in H \\ s=1, \ldots, n}}{ },\left(Y_{f, t}\right)_{\substack{f \in F \\ t=1, \ldots, n}},\left(\theta_{h, s, f, t}\right)_{\substack{h \in H, f \in F \\ s, t=1, \ldots, n}}\right)
$$

with the following characteristics:

- The economy $\mathcal{E}_{n}$ has the same commodity-price duality $\left\langle L \times \mathbb{R}^{K}, L^{\prime} \times \mathbb{R}^{K}\right\rangle$ as $\mathcal{E}$.

- For each $f \in F, n$ firms, each one indexed by $(f, t)(t=1, \ldots, n)$, have the same production set: $Y_{f, t}:=Y_{f}$

- For each $h \in H, n$ households of type $h$, each one indexed by $(h, s)(s=1, \ldots, n)$, have the same choice set $X_{h, s}:=X_{h}=L_{+} \times \mathbb{R}_{+}^{K}$ and the same initial endowment $e_{h, s}:=e_{h}=$ $\left(\omega_{h}, 0\right) \in L_{+} \times\{0\}$. 
- For ownership of initial holdings and production possibilities, each household $(h, s)$ is a copy of $h$, but restricted within his subeconomy: ${ }^{2} \theta_{h, s, f, t}$ is defined by

$$
\theta_{h, s, f, t}=0 \text { if } s \neq t \text { and } \theta_{h, s, f, t}=\theta_{h, f} \text { if } s=t .
$$

- The definition of consumers' preferences is specific of an economy with public goods. For a consumer $(h, s)$, the utility associated with a choice $\left(x_{h, s}, x_{h, s}^{g}\right)$ is the utility

$$
u_{h}\left(x_{h, s}, \frac{1}{n} \sum_{\left(h^{\prime}, s^{\prime}\right) \in H \times\{1, \ldots, n\}} x_{h^{\prime}, s^{\prime}}^{g}\right)
$$

corresponding to the private commodity consumption $x_{h, s}$ and the mean of the aggregate public good provision in the whole economy. Such a definition is quite similar to the one proposed by Vasil'ev (1994-96), justified by the idea that for most of public goods, the appreciation we have about their "size" is dependent on the size of the economy we are talking about (see Milleron 1972). For the same consumer $(h, s)$, considered as belonging to a coalition $T \subset H \times\{1, \ldots, n\}$, the utility associated with the same choice $\left(x_{h, s}, x_{h, s}^{g}\right)$ is the mean of the aggregate public good provision in the coalition over the number of consumers of type $h$ in this coalition, that is

$$
u_{h}\left(x_{h, s}, \frac{1}{|T(h)|} \sum_{\left(h^{\prime}, s^{\prime}\right) \in T} x_{h^{\prime}, s^{\prime}}^{g}\right)
$$

where $T(h):=\{s \in\{1, \ldots, n\}:(h, s) \in T\}$ and $|T(h)|$ denotes the number of elements of $T(h)$. In other words, the appreciation of a consumer of type $h$ about the provision of public goods is now dependent on the size of the group of consumers of his type in the coalition.

According to this definition, blocking in replica economies is defined as follows:

Definition 3.5. A coalition $T \subset H \times\{1, \ldots, n\}$ improves upon or blocks a feasible consumption allocation $\left(\left(\bar{x}_{h, 1}, \bar{x}_{h, 1}^{g}\right)_{h \in H}, \ldots,\left(\bar{x}_{h, n}, \bar{x}_{h, n}^{g}\right)_{h \in H}\right)$ of $\mathcal{E}_{n}$ if there is some $\left(y_{f, t}, y_{f, t}^{g}\right) \in Y_{f}$ for each $f \in F, t \in\{1, \ldots, n\}$, and some $\left(x_{h, s}, x_{h, s}^{g}\right)_{(h, s) \in T} \in L_{+}^{T} \times\left(\mathbb{R}_{+}^{K}\right)^{T}$ such that

$$
\sum_{(h, s) \in T}\left(x_{h, s}, x_{h, s}^{g}\right)=\sum_{h \in H}|T(h)|\left(\omega_{h}, 0\right)+\sum_{(h, s) \in T} \sum_{f \in F} \theta_{h, f}\left(y_{f, s}, y_{f, s}^{g}\right)
$$

and

$$
u_{h}\left(x_{h, s}, \frac{1}{|T(h)|} \sum_{\left(h^{\prime}, s^{\prime}\right) \in T} x_{h^{\prime}, s^{\prime}}^{g}\right)>u_{h}\left(\bar{x}_{h, s}, \frac{1}{n} \sum_{\left(h^{\prime}, s^{\prime}\right) \in H \times\{1, \ldots, n\}} \bar{x}_{h^{\prime}, s^{\prime}}^{g}\right) \text { for each }(h, s) \in T
$$

In other words, a coalition $T$ blocks the feasible $\left(\bar{x}_{h, s}, \bar{x}_{h, s}^{g}\right)_{(h, s) \in H \times\{1, \ldots, n\}}$ if its members can consume some amount of private goods $\left(x_{h, s}\right)_{(h, s) \in T}$ and claim some weighted amount of public goods that they unanimously prefer and can afford using their own resources.

In relation (3.1), define $G^{T}=\sum_{(h, s) \in T} x_{h, s}^{g}$. It will be convenient to speak of the pair $\left(\left(x_{h, s}\right)_{(h, s) \in T}, G^{T}\right)$ as a $T$-feasible pair.

\footnotetext{
${ }^{2}$ This definition is coherent with the definitions given by Aliprantis, Brown and Burkinshaw (1987) or Florenzano (1990).
} 
Definition 3.6. The core $\mathcal{C}\left(\mathcal{E}_{n}\right)$ is the set of all feasible allocations (alternatively, the set of all feasible pairs) of $\mathcal{E}_{n}$ which are blocked by no coalition $T \subset H \times\{1, \ldots, n\}$.

Finally, let $\left(\bar{x}_{h}, \bar{x}_{h}^{g}\right)_{h \in H}$ be a feasible consumption allocation of $\mathcal{E}$. Then, for any positive integer $n$, we can define for each household $(h, s) \in H \times\{1, \ldots, n\}, \bar{x}_{h, s}=\bar{x}_{h}$ and $\bar{x}_{h, s}^{g}=\bar{x}_{h}^{g}$. It is easy to see that the consumption allocation so obtained

$$
\left(\left(\bar{x}_{h, 1}, \bar{x}_{h, 1}^{g}\right)_{h \in H}, \ldots,\left(\bar{x}_{h, n}, \bar{x}_{h, n}^{g}\right)_{h \in H}\right)=\left(\left(\bar{x}_{h}, \bar{x}_{h}^{g}\right)_{h \in H}, \ldots,\left(\bar{x}_{h}, \bar{x}_{h}^{g}\right)_{h \in H}\right)
$$

is a feasible consumption allocation of $\mathcal{E}_{n}$, called $n$-equal treatment allocation in $\mathcal{E}_{n}$ because it gives the same choice $\left(\bar{x}_{h}, \bar{x}_{h}^{g}\right)$ to each of the $n$ consumers of type $h$.

Definition 3.7. For each integer $n \geq 1, \mathcal{C}^{n}(\mathcal{E})$ is the set of all feasible consumption allocations of $\mathcal{E}$ such that the corresponding $n$-equal treatment consumption allocation of $\mathcal{E}_{n}$ belongs to $\mathcal{C}\left(\mathcal{E}_{n}\right)$.

We are now ready to give the definition of Edgeworth equilibria of $\mathcal{E}$.

Definition 3.8. A feasible consumption allocation $\left(\bar{x}_{h}, \bar{x}_{h}^{g}\right)_{h \in H}$ (alternatively, a feasible pair $\left(\left(\bar{x}_{h}\right)_{h \in H}, \bar{G}\right)$ where $\left.\bar{G}=\sum_{h \in H} \bar{x}_{h}^{g}\right)$ is said to be an Edgeworth equilibrium of $\mathcal{E}$ whenever the corresponding $n$-equal treatment consumption allocation, that is, its $n$-replica, belongs to $\mathcal{C}\left(\mathcal{E}_{n}\right)$ for every $n$-fold replica economy $\mathcal{E}_{n}$ of $\mathcal{E}$. We denote by $\mathcal{C}^{E}(\mathcal{E})$ the set of the Edgeworth equilibria of $\mathcal{E}$.

One easily verifies that for every $n, \mathcal{C}^{n+1}(\mathcal{E}) \subset \mathcal{C}^{n}(\mathcal{E})$ and thus that

$$
\mathcal{C}^{E}(\mathcal{E})=\bigcap_{n \geq 1} \mathcal{C}^{n}(\mathcal{E}) \subset \ldots \subset \mathcal{C}^{n+1}(\mathcal{E}) \subset \mathcal{C}^{n}(\mathcal{E}) \subset \ldots \subset \mathcal{C}(\mathcal{E}) .
$$

The non-emptiness of $\mathcal{C}^{E}(\mathcal{E})$ under the standard assumptions on $\mathcal{E}$ is proved in the next section.

\section{NON-EMPTINESS THEOREMS}

When preferences are represented by utility functions, existence of Edgeworth equilibria is based on the celebrated Theorem 1 of Scarf (1967) on the non-emptiness of the core of a balanced game. In an infinite dimensional setting, that is the strategy followed by Aliprantis, Brown and Burkinshaw (1987) for a private ownership production economy, by Allouch and Florenzano (2004) for an arbitrage-free exchange economy. We will adapt here Allouch-Florenzano's strategy to our production economy with private provisions of pure public goods. One can find in the $\mathrm{PhD}$ thesis of del Mercato (2004), with a different notion of Edgeworth equilibrium and under the assumption that the commodity-space duality $\left\langle L, L^{\prime}\right\rangle$ is a symmetric Riesz dual system, an adaptation of Aliprantis-Brown-Burkinshaw's strategy to our public good economy. Monotonicity of utility functions with respect to private and public goods plays a decisive role in this adaptation.

Actually, we will use an extension of Scarf's theorem to finite fuzzy games. Before recalling its statement, we need to introduce some notation. Let $M=\{1, \ldots, m\}$ be a finite set of players and $\mathcal{T}^{M}=[0,1]^{m} \backslash\{0\}$. An element $t \in \mathcal{T}^{M}$ is interpreted as a fuzzy coalition, that is, a vector $t=\left(t_{i}\right)_{i=1}^{m}$ of rates of participation to the coalition $t$ for the different players. We are interested in finite subsets $\mathcal{T}$ of $\mathcal{T}^{M}$ containing the vector $\overline{1}=(1, \ldots, 1)$ of rates of participation to the grand coalition and the canonical base $\left(e^{i}\right)$ of $\mathbb{R}^{m}$, each $e^{i}$ being the vector of rates of participation to the coalition $\{i\}$. A nonempty-valued correspondence $V: \mathcal{T} \rightarrow \mathbb{R}^{m}$ defines a fuzzy game $(\mathcal{T}, V)$. The fuzzy core $\mathcal{C}(\mathcal{T}, V)$ of the $m$-person fuzzy game $(\mathcal{T}, V)$ is defined as the set

$$
\mathcal{C}(\mathcal{T}, V):=\left\{v \in V(\overline{1}): \quad \nexists t \in \mathcal{T} \text { and } u \in V(t) \text { s.t. } v_{i}<u_{i}, \forall i: t_{i}>0\right\}
$$


Let

$$
\triangle^{\mathcal{T}}=\left\{\left(\lambda_{t}\right)_{t \in \mathcal{T}}: \quad \lambda_{t} \geq 0 \text { and } \sum_{t \in \mathcal{T}} \lambda_{t} t=1\right\} .
$$

The $m$-person fuzzy game $(\mathcal{T}, V)$ is said to be balanced whenever for every $\lambda \in \Delta^{\mathcal{T}}$,

$$
\bigcap_{\left\{t \in \mathcal{T}: \lambda_{t}>0\right\}} V(t) \subset V(\overline{1}) .
$$

The following theorem, proved in Allouch and Florenzano (2004), extends Scarf's theorem as stated by Aliprantis, Brown and Burkinshaw (1989).

Theorem 4.1. If $\mathcal{T}$ is as above and if $(\mathcal{T}, V)$ is a balanced m-person fuzzy game such that

(a) each $V(t)$ is closed,

(b) each $V(t)$ is comprehensive from below, i.e., $u \leq v$ and $v \in V(t)$ imply $u \in V(t)$,

(c) $u \in R^{m}, v \in V(t)$ and $u_{i}=v_{i} \forall i: t_{i}>0$ imply $u \in V(t)$,

(d) for each $t \in \mathcal{T}$ there exists $c_{t} \in R$, such that $v \in V(t)$ implies $v_{i} \leq c_{t}$ for all $i: t_{i}>0$, then

$$
\mathcal{C}(\mathcal{T}, V) \neq \varnothing
$$

Coming back to our model, let

$$
\mathcal{U}=\left\{v \in \mathbb{R}^{H}: \exists\left(x_{h}, x_{h}^{g}\right)_{h \in H} \in \widehat{X} \text { s.t. } u_{h}\left(\omega_{h}, 0\right) \leq v_{h} \leq u_{h}\left(x_{h}, \sum_{h^{\prime} \in H} x_{h^{\prime}}^{g}\right), \forall h \in H\right\} .
$$

Letting $G=\sum_{h \in H} x_{h}^{g}$, one can also write with some abuse of language:

$$
\mathcal{U}=\left\{v \in \mathbb{R}^{H}: \exists\left(\left(x_{h}\right)_{h \in H}, G\right) \in \widehat{X} \text { s.t. } u_{h}\left(\omega_{h}, 0\right) \leq v_{h} \leq u_{h}\left(x_{h}, G\right), \forall h \in H\right\} .
$$

Noticing that inaction is possible (Assumptions $\mathbf{A 1}$ and A2), this set can be thought of as the set of vectors of feasible and individually rational utilities.

To each coalition $T \subset H \times\{1, \ldots, n\}$ of the $n$-replica economy $\mathcal{E}_{n}$ of $\mathcal{E}$ is associated a vector of rates of participation belonging to the set

$$
\mathcal{T}_{n}=\left\{t=\left(t_{h}\right)_{h \in H}: n t_{h} \in\{0,1, \ldots, n\}, \forall h \in H\right\} .
$$

We will denote by $\overline{1}$ the vector of rates of participation to the grand coalition $H$. The $h$-th vector of the canonical base of $\mathbb{R}^{H}, e^{h}$, is the vector of rates of participation to the coalition $\{h\}$ containing the only one participant $h$.

For each $t \in \mathcal{T}_{n}$, letting $\operatorname{supp} t=\left\{h \in H: t_{h}>0\right\}$, we define successively:

$$
\begin{gathered}
\widehat{X}_{t}=\left\{\left(\left(x_{h}^{t}\right)_{h \in \operatorname{supp} t}, G^{t}\right) \in L_{+}^{\text {supp } t} \times \mathbb{R}_{+}^{K}:\left(\sum_{h \in H} t_{h} x_{h}^{t}, G^{t}\right) \in \sum_{h \in H} t_{h}\left(\omega_{h}, 0\right)+\sum_{h \in H} t_{h} \sum_{f \in F} \theta_{h, f} Y_{f}\right\} ; \\
\mathcal{U}_{t}=\left\{\left(v_{h}\right) \in \mathbb{R}^{\text {supp } t}: \exists\left(\left(x_{h}^{t}\right)_{h \in \operatorname{supp} t}, G^{t}\right) \in \widehat{X}_{t} \text { s.t. } u_{h}\left(\omega_{h}, 0\right) \leq v_{h} \leq u_{h}\left(x_{h}^{t}, \frac{G^{t}}{t_{h}}\right), \forall h \in \operatorname{supp} t\right\} ; \\
V(t)=\operatorname{cl}\left(\mathcal{U}_{t}-\mathbb{R}_{+}^{\text {supp } t}\right) \times \mathbb{R}^{H \backslash \operatorname{supp} t .}
\end{gathered}
$$

It easily follows from Assumptions $\mathbf{A} \mathbf{1}$ and $\mathbf{A} \mathbf{3}$ that $\mathcal{U}$ is compact. Also, each $\widehat{X}_{e^{h}} \subset \widehat{X}_{h}$ is relatively $\left(\sigma \times \tau_{\mathbb{R}^{K}}\right)^{H}$-compact, so that it also follows from Assumption $\mathbf{A} \mathbf{1}$ that $\mathcal{U}_{e^{h}}$ is relatively compact. 
Thus there exists $c>\max _{h \in H} u_{h}\left(\omega_{h}, 0\right)$ such that $\left.\mathcal{U} \subset\right]-\infty, c\left[{ }^{H}\right.$ and $\left.\mathcal{U}_{e^{h}} \subset\right]-\infty, c[$, for each $h \in H$. We now define

$$
\left.\left.V^{c}(t)=\left(\operatorname{cl}\left(\mathcal{U}_{t}-\mathbb{R}_{+}^{\text {supp } t}\right) \bigcap(]-\infty, c\right]\right)^{\operatorname{supp} t}\right) \times \mathbb{R}^{H \backslash \operatorname{supp} t} .
$$

We will apply Theorem 4.1 to the fuzzy game $\left(\mathcal{T}_{n}, V^{c}\right)$.

Proposition 4.1. Under the standard assumptions on $\mathcal{E}$, for every integer $n \geq 1$ the fuzzy core $\mathcal{C}\left(\mathcal{T}_{n}, V^{c}\right)$ is non-empty. Consequently, $\mathcal{C}\left(\mathcal{T}_{n}, V\right) \neq \varnothing$.

Proof. By construction, the fuzzy game $\left(\mathcal{T}_{n}, V^{c}\right)$ verifies the conditions a, b, c, d of Theorem 4.1. It suffices to verify that the fuzzy game $\left(\mathcal{T}_{n}, V^{c}\right)$ is balanced. To this end, let $\lambda \in \triangle^{\mathcal{T}_{n}}$ and $v \in \bigcap_{\left\{t \in \mathcal{T}_{n}: \lambda_{t}>0\right\}} V^{c}(t)$. For each integer $\nu$ and for every $t \in \mathcal{T}_{n}$ such that $\lambda_{t}>0$, there exists $\left(\left(x_{h}^{t, \nu}\right)_{h \in \operatorname{supp} t}, G^{t, \nu}\right) \in \widehat{X}_{t}$ such that for every $h \in \operatorname{supp} t$,

$$
u_{h}\left(x_{h}^{t, \nu}, \frac{G^{t, \nu}}{t_{h}}\right) \geq u_{h}\left(\omega_{h}, 0\right) \text { and } v_{h} \leq u_{h}\left(x_{h}^{t, \nu}, \frac{G^{t, \nu}}{t_{h}}\right)+\frac{1}{\nu} .
$$

For each $h \in H$, let

$$
x_{h}^{\nu}=\sum_{t \in \mathcal{T}_{n}} \lambda_{t} t_{h} x_{h}^{t, \nu} .
$$

Let also $G^{\nu}=\sum_{t \in \mathcal{T}_{n}} \lambda_{t} G^{t, \nu}$. Using the definition of $\triangle^{\mathcal{T}_{n}}$ and the convexity of each production set $Y_{f}$, one has:

$$
\begin{gathered}
\left(\sum_{h \in H} x_{h}^{\nu}, G^{\nu}\right)=\left(\sum_{h \in H} \sum_{t \in \mathcal{T}_{n}} \lambda_{t} t_{h} x_{h}^{t, \nu}, \sum_{t \in \mathcal{T}_{n}} \lambda_{t} G^{t, \nu}\right) \\
=\left(\sum_{t \in \mathcal{T}_{n}} \lambda_{t} \sum_{h \in H} t_{h} x_{h}^{t, \nu}, \sum_{t \in \mathcal{T}_{n}} \lambda_{t} G^{t, \nu}\right) \\
\in\left(\sum_{t \in \mathcal{T}_{n}} \lambda_{t} \sum_{h \in H} t_{h} \omega_{h}, 0\right)+\sum_{t \in \mathcal{T}_{n}} \lambda_{t} \sum_{h \in H} t_{h} \sum_{f \in F} \theta_{h, f} Y_{f} \\
\in \sum_{h \in H}\left(\omega_{h}, 0\right)+\sum_{f \in F} \sum_{h \in H} \theta_{h, f} \sum_{t \in \mathcal{T}_{n}} \lambda_{t} t_{h} Y_{f} \\
\in \sum_{h \in H}\left(\omega_{h}, 0\right)+\sum_{f \in F} \sum_{h \in H} \theta_{h, f} Y_{f},
\end{gathered}
$$

which proves that $\left(\left(x_{h}^{\nu}\right)_{h \in H}, G^{\nu}\right) \in \widehat{X}$.

On the other hand, notice that for each $h \in H$,

$$
G^{\nu}=\sum_{t \in \mathcal{T}_{n}} \lambda_{t} G^{t, \nu}=\sum_{\substack{t \in \mathcal{T}_{n} \\ t_{h} \neq 0}} \lambda_{t} G^{t, \nu}+\sum_{\substack{t \in \mathcal{T}_{n} \\ t_{h}=0}} \lambda_{t} G^{t, \nu}
$$

It then follows from the monotonicity with respects to public goods and the quasiconcavity of each $u_{h}$ and the definition of $\triangle^{\mathcal{T}_{n}}$ that $u_{h}\left(x_{h}^{\nu}, G^{\nu}\right) \geq u_{h}\left(\omega_{h}, 0\right)$ and $v_{h} \leq u_{h}\left(x_{h}^{\nu}, G^{\nu}\right)+\frac{1}{\nu}$, which shows that $\left(u_{h}\left(x_{h}^{\nu}, G^{\nu}\right)\right)_{h \in H} \in \mathcal{U}$. Recalling that $\mathcal{U}$ is compact and passing to a subsequence if necessary, we get that for some $\left(\left(x_{h}\right)_{h \in H}, G\right) \in \widehat{X}$ and for each $h \in H$,

$$
v_{h} \leq \lim _{\nu \rightarrow+\infty} u_{h}\left(x_{h}^{\nu}, G^{\nu}\right) \leq u_{h}\left(x_{h}, G\right) .
$$

Hence $v=\left(v_{h}\right)_{h \in H} \in V(\overline{1})=V^{c}(\overline{1})$, which shows that the fuzzy game $\left(\mathcal{T}_{n}, V^{c}\right)$ is balanced and that $\mathcal{C}\left(\mathcal{T}_{n}, V^{c}\right) \neq \varnothing$. 
To prove the last assertion, let $v=\left(v_{h}\right)_{h \in H} \in \mathcal{C}\left(\mathcal{T}_{n}, V^{c}\right)$. Note that $v \in V^{c}(\overline{1})=V(\overline{1})=\mathcal{U}-\mathbb{R}_{+}^{H}$. Moreover $v \in \mathcal{U}$. Indeed, if not, for some $h_{0} \in H, u_{h_{0}}\left(\omega_{h_{0}}, 0\right)>v_{h_{0}}$ and $\left(u_{h}\left(\omega_{h}, 0\right)\right)_{h \in H} \in V\left(e^{h_{0}}\right)=$ $V^{c}\left(e^{h_{0}}\right)$, in contradiction with $v \in \mathcal{C}\left(\mathcal{T}_{n}, V^{c}\right)$. We now prove by contraposition that $v \in \mathcal{C}\left(\mathcal{T}_{n}, V\right)$. Let us assume on the contrary that there exist $t \in \mathcal{T}_{n}$ and $u \in V(t)$ such that $v_{h}<u_{h}, \forall h \in \operatorname{supp} t$. We have $v_{h}<u_{h} \forall h \in \operatorname{supp} t$ and $u_{h}\left(\omega_{h}, 0\right) \leq v_{h}<c \forall h \in H$. Let $\lambda>0$ be such that $v_{h}<v_{h}+\lambda\left(c-u_{h}\left(\omega_{h}, 0\right)<\min \left\{u_{h}, c\right\} \quad \forall h \in \operatorname{supp} t\right.$. Then $\left(v_{h}+\lambda\left(c-u_{h}\left(\omega_{h}, 0\right)\right)_{h \in H} \in V^{c}(t)\right.$, in contradiction with $v \in \mathcal{C}\left(\mathcal{T}_{n}, V^{c}\right)$.

Proposition 4.2. Under the standard assumptions on $\mathcal{E}, \bigcap_{n \geq 1} \mathcal{C}\left(\mathcal{T}_{n}, V\right) \neq \varnothing$.

Proof. Let us first show that $\mathcal{C}\left(\mathcal{T}_{n}, V\right)$ is closed. Let $v=\lim _{\nu \rightarrow+\infty} v^{\nu}$ with $v^{\nu} \in \mathcal{C}\left(\mathcal{T}_{n}, V\right)$. If $v \notin \mathcal{C}\left(\mathcal{T}_{n}, V\right)$, then there exist $t \in \mathcal{T}_{n}$ and $u \in V(t)$ such that $v_{h}<u_{h} \forall h \in \operatorname{supp} t$. For $\nu$ large enough, $v_{h}^{\nu}<u_{h} \forall h \in \operatorname{supp} t$, a contradiction. To end the proof, in view of the compactness of $\mathcal{U}$, it suffices to prove that for each integer $n \geq 1, \mathcal{C}\left(\mathcal{T}_{n+1}, V\right) \subset \mathcal{C}\left(\mathcal{T}_{n}, V\right)$. Let $v \in \mathcal{C}\left(\mathcal{T}_{n+1}, V\right)$. If $v \notin \mathcal{C}\left(\mathcal{T}_{n}, V\right)$, there exist $t \in \mathcal{T}_{n}$ and $u \in V(t)$ such that $v_{h}<u_{h} \forall h \in \operatorname{supp} t$. Let us consider $t^{\prime}=\frac{n}{n+1} t$. If $\left(\left(x_{h}^{t}\right)_{h \in \operatorname{supp} t}, G^{t}\right) \in \widehat{X}_{t}$ and if $x_{h}^{t^{\prime}}=x_{h}^{t}, G^{t^{\prime}}=\frac{n}{n+1} G^{t}$, then $\left(\left(x_{h}^{t^{\prime}}\right)_{h \in \operatorname{supp} t}, G^{t^{\prime}}\right) \in \widehat{X}_{t^{\prime}}$. Conversely, if $\left(\left(x_{h}^{t^{\prime}}\right)_{h \in \operatorname{supp} t}, G^{t^{\prime}}\right) \in \widehat{X}_{t^{\prime}}$ and if $x_{h}^{t}=x_{h}^{t^{\prime}}, G^{t}=\frac{n+1}{n} G^{t^{\prime}}$, then $\left(\left(x_{h}^{t}\right)_{h \in \operatorname{supp} t}, G^{t}\right) \in \widehat{X}_{t}$. Now, clearly, $\mathcal{U}_{t^{\prime}}=\mathcal{U}_{t}$ and $V\left(t^{\prime}\right)=V(t)$. Since $t^{\prime} \in \mathcal{T}_{n+1}$ and $u \in V\left(t^{\prime}\right)$, we have got a contradiction.

We are now ready to prove the main result of this section.

Theorem 4.2. Under the standard assumptions on $\mathcal{E}$, the set $\mathcal{C}^{E}(\mathcal{E})$ of Edgeworth equilibria of $\mathcal{E}$ is non-empty.

Proof. Let $\bar{v} \in \bigcap_{n \geq 1} \mathcal{C}\left(\mathcal{T}_{n}, V\right)$. As already noticed, $\bar{v} \in \mathcal{U}$ and there exists $\left(\left(\bar{x}_{h}\right)_{h \in H}, \bar{G}\right) \in \widehat{X}$ such that for each $h \in H, u_{h}\left(\omega_{h}, 0\right) \leq \bar{v}_{h} \leq u_{h}\left(\bar{x}_{h}, \bar{G}\right)$. We claim that $\left(\left(\bar{x}_{h}\right)_{h \in H}, \bar{G}\right) \in \mathcal{C}^{E}(\mathcal{E})$. Assume on the contrary, that for some $n \geq 1,\left(\left(\bar{x}_{h}\right)_{h \in H}, \bar{G}\right) \notin \mathcal{C}^{n}(\mathcal{E})$. Coming back to Definitions 3.5 and 3.7, there exist $T \subset H \times\{1, \ldots, n\}$ and $\left(x_{h, s}, x_{h, s}^{g}\right)_{(h, s) \in T}$ satisfying relations (3.1) and (3.2). Let $G^{T}=\sum_{(h, s) \in T} x_{h, s}$ be the aggregate amount of provisions of public goods by the members of $T$ and $G^{t}=\frac{1}{n} G^{T}$. Letting for each $h: T(h) \neq \varnothing$ and for each $f \in F, t_{h}=\frac{|T(h)|}{n}, x_{h}^{t}=\frac{1}{|T(h)|} \sum_{s \in T(h)} x_{h, s}$, $\left(y_{f}^{t}, y_{f}^{g, t}\right)=\frac{1}{|T(h)|} \sum_{s \in T(h)}\left(y_{f, s}, y_{f, s}^{g}\right)$, relations (3.1) and (3.2) can easily be rewritten:

$$
\left(\sum_{h \in H} t_{h} x_{h}^{t}, G^{t}\right)=\sum_{h \in H} t_{h}\left(\omega_{h}, 0\right)+\sum_{h \in H} t_{h} \sum_{f \in F} \theta_{h, f}\left(y_{f}^{t}, y_{f}^{g, t}\right)
$$

where, in view of the convexity of $Y_{f}$, each $\left(y_{f}, y_{f}^{g}\right) \in Y_{f}$, and, using the quasi-concavity of each $u_{h}$,

$$
u_{h}\left(x_{h}^{t}, \frac{1}{t_{h}} G^{t}\right)>u_{h}\left(\bar{x}_{h}, \bar{G}\right) .
$$

Relations (4.1) and (4.2) show that $\bar{v} \notin \mathcal{C}\left(\mathcal{T}_{n}, V\right)$, a contradiction.

Remark 4.3. It is worth noticing that, at this stage, the private provisions which sum to $\bar{G}$ in the pair $\left(\left(\bar{x}_{h}\right)_{h \in H}, \bar{G}\right)$ do not need to be precise. In the next section, we will determine the private 
provisions which sum to $\bar{G}$ when the Edgeworth equilibrium pair $\left(\left(\bar{x}_{h}\right)_{h \in H}, \bar{G}\right)$ is decentralized as the consumption component of a Lindahl-Foley equilibrium.

\section{Decentralizing Edgeworth equilibria as Lindahl-Foley equilibria}

Let us first introduce the following equilibrium definition.

Definition 5.1. A Lindahl-Foley equilibrium of $\mathcal{E}$ is a t-uple

$$
\left(\left(\bar{x}_{h}\right)_{h \in H},\left(\bar{t}_{h}\right)_{h \in H}, \bar{G},\left(\bar{y}_{f}, \bar{y}_{f}^{g}\right)_{f \in F},\left(\bar{p}, \bar{p}^{g}\right)\right) \in\left(L_{+}\right)^{H} \times[0,1]^{H} \times \mathbb{R}_{+}^{K} \times \prod_{f \in F} Y_{f} \times\left(L^{\prime} \times \mathbb{R}^{K}\right)
$$

such that:

(1) for every $f \in F$, for every $\left(y_{f}, y_{f}^{g}\right) \in Y_{f},\left(\bar{p}, \bar{p}^{g}\right) \cdot\left(y_{f}, y_{f}^{g}\right) \leq\left(\bar{p}, \bar{p}^{g}\right) \cdot\left(\bar{y}_{f}, \bar{y}_{f}^{g}\right)$,

(2) for every $h \in H,\left(\bar{x}_{h}, \bar{G}\right)$ maximizes $u_{h}\left(x_{h}, G\right)$ in the budget set

$$
B_{h}\left(\bar{t}_{h},\left(\bar{p}, \bar{p}_{g}\right)\right)=\left\{\left(x_{h}, G\right) \in L_{+} \times \mathbb{R}_{+}^{K}: \bar{p} \cdot x_{h}+\bar{t}_{h} \bar{p}^{g} \cdot G \leq \bar{p} \cdot \omega_{h}+\sum_{f \in F} \theta_{h, f}\left(\bar{p}, \bar{p}^{g}\right) \cdot\left(\bar{y}_{f}, \bar{y}_{f}^{g}\right)\right\},
$$

(3) $\bar{G}=\sum_{f \in F} \bar{y}_{f}^{g} ; \sum_{h \in H} \bar{t}_{h}=1 ; \sum_{h \in H} \bar{x}_{h}=\sum_{h \in H} \omega_{h}+\sum_{f \in F} \bar{y}_{f}$.

If, in the previous definition, we set $\bar{x}_{h}^{g}=\bar{t}_{h} \bar{G}$, then each $\bar{x}_{h}^{g}$ can be thought of as $h$ 's provision of public goods and condition 3 in the previous definition means that the allocation

$$
\left(\left(\bar{x}_{h}, \bar{x}_{h}^{g}\right)_{h \in H},\left(\bar{y}_{f}, \bar{y}_{f}^{g}\right)_{f \in F}\right)
$$

is a feasible allocation of $\mathcal{E}$. One can also say that $\left(\left(\bar{x}_{h}\right)_{h \in H}, \bar{G},\left(\bar{y}_{f}, \bar{y}_{f}^{g}\right)_{f \in F}\right)$ is a feasible LindahlFoley allocation and that the pair $\left(\left(\bar{x}_{h}\right)_{h \in H}, \bar{G}\right)$ is a feasible Lindahl-Foley consumption allocation.

If we set $\bar{p}_{h}^{g}=\bar{t}_{h} \bar{p}^{g}$, each $\bar{p}_{h}^{g}$ can be thought of as a personalized vector of public good prices as in the classical definition (See for example Milleron 1972, Section 3) of Lindahl-Foley equilibrium. Then in both cases, Condition 1 means that each firm maximizes its profit taking as given the common vector price $\left(\bar{p}, \bar{p}^{g}\right)$. Condition 2 means that each consumer chooses a consumption of private goods and claims a total amount of public goods, so as to maximize his utility function taking as given the common price of private goods and his personalized price of public goods (equivalently, the relative part of public goods he accepts to provide). Equilibrium is characterized by feasibility of the allocation and a unanimous consent on the amount of public goods to be produced.

It is worth noticing that the equilibrium definition 5.1 dramatically differs by the setting of household $h$ 's optimization problem from the more classical general equilibrium concept studied in Villanacci and Zenginobuz (2001) where, for a common vector price $\left(\bar{p}, \bar{p}^{g}\right)$, each household is assumed to choose his provision of public goods so as to maximize his utility function, taking as given the provisions of public goods of the other agents. ${ }^{3}$ In contrast with results of Villanacci and Zenginobuz (2003), it simply follows from the definitions that a Lindahl-Foley equilibrium of $\mathcal{E}$ is Pareto optimal, belongs to the core and is an Edgeworth equilibrium, for the optimality and core notions defined in Section 3. The purpose of this section is to prove converse results. More

\footnotetext{
${ }^{3}$ Identifying consumption and provision of public goods, a careful reader will notice that the VillanacciZenginobuz equilibrium can be analyzed as a general equilibrium of a production economy where, as in Florenzano (1990), preferences of the agents depend on the consumptions of the other agents.
} 
precisely, it is to associate with an Edgeworth equilibrium of $\mathcal{E}$ private good prices and personalized public good prices so as to get a Lindahl-Foley equilibrium.

5.1. Definition of an associated economy $\mathcal{E}^{\prime}$ with only private commodities. Following Foley (1970) and Milleron (1972), we now define an economy $\mathcal{E}^{\prime}$ with only private commodities such that there is a one-to-one correspondence between the feasible allocations in this economy and the feasible Lindahl-Foley allocations in the original model $\mathcal{E}$.

We first extend the commodity space by considering each consumer's bundle of public goods as a separate group of commodities. The consumption set of consumer $h$ is then extended by writing for all public good components not corresponding to the $h$ th component hypothetic bundles of public goods $G_{h^{\prime}, h}$ which do not enter as arguments in the utility function of $h$ :

$$
X_{h}^{\prime}=\left\{x_{h}^{\prime} \in L_{+} \times\left(\mathbb{R}_{+}^{K}\right)^{H}: x_{h}^{\prime}=\left(x_{h},\left(G_{1, h}, \ldots, G_{H, h}\right)\right)\right\},
$$

Production sets, initial endowments and utility functions are defined as follows:

$$
\begin{aligned}
& Y_{f}^{\prime}=\left\{y_{f}^{\prime} \in L \times\left(\mathbb{R}^{K}\right)^{H}: \exists\left(y_{f}, y_{f}^{g}\right) \in Y_{f}, y_{f}^{\prime}=\left(y_{f},\left(y_{1, f}^{g}, \ldots, y_{H, f}^{g}\right), y_{h, f} \leq y_{f}^{g} \forall h \in H\right\} ;\right. \\
& e_{h}^{\prime}=\left(\omega_{h},(0, \ldots, 0)\right) ; u_{h}^{\prime}\left(x_{h}^{\prime}\right)=u_{h}\left(x_{h}, G_{h, h}\right) .
\end{aligned}
$$

Finally,

$$
\mathcal{E}^{\prime}=\left(\left\langle L \times\left(\mathbb{R}^{K}\right)^{H}, L^{\prime} \times\left(\mathbb{R}^{K}\right)^{H}\right\rangle,\left(X_{h}^{\prime}, u_{h}^{\prime}, e_{h}^{\prime}\right)_{h \in H},\left(Y_{f}^{\prime}\right)_{f \in F},\left(\theta_{h, f}\right)_{\substack{h \in H \\ f \in F}}\right) .
$$

The relations between weakly Pareto optimal, core and Edgeworth (feasible) Lindahl-Foley allocations of $\mathcal{E}$ as defined in Section 3 on one hand, and on the other hand, weakly Pareto optimal, core and Edgeworth equilibrium allocations of $\mathcal{E}^{\prime}$, as usually defined, are summarized in the next proposition. Its proof is straightforward, if one cautiously overcomes notational difficulties. The results strongly rely on the assumption of monotonicity of utility functions with respect to public goods.

Proposition 5.1. Under the standard assumptions on $\mathcal{E}$, we have the following:

(a) Let $\varnothing \neq S \subset H$ be a coalition. If $\left(\left(x_{h}\right)_{h \in S}, G^{S}\right)$ is $S$-feasible in $\mathcal{E}$, the consumption assignment $\left(x_{h}^{\prime}\right)_{h \in S}$ where for each $h \in S, x_{h}^{\prime}=\left(x_{h},\left(0, \ldots, G^{S}, \ldots, 0\right)\right)$, that we will call in the sequel the corresponding $\left(x_{h}^{\prime}\right)_{h \in S}$, is $S$-feasible in $\mathcal{E}^{\prime}$. Conversely, if some $\left(x_{h}^{\prime}\right)_{h \in S}$ is $S$-feasible in $\mathcal{E}^{\prime}$, with $x_{h}^{\prime}=\left(x_{h},\left(G_{1, h}, \ldots, G_{H, h}\right)\right) \in X_{h}^{\prime}$ for each $h \in S$, then there exists $G^{S} \in \mathbb{R}_{+}^{K}$ such that $\left(\left(x_{h}\right)_{h \in S}, G^{S}\right)$ is $S$-feasible in $\mathcal{E}$. Moreover, $G^{S} \geq G_{h, h} \forall h \in S$.

(b) In particular, if $\left(\left(\bar{x}_{h}\right)_{h \in H}, \bar{G}\right)$ is Lindahl-Foley feasible in $\mathcal{E}$, the corresponding $\left(\bar{x}_{h}^{\prime}\right)_{h \in H}$ is feasible in $\mathcal{E}^{\prime}$. Conversely, if $\left(\bar{x}_{h}^{\prime}\right)_{h \in H}$ is feasible in $\mathcal{E}^{\prime}$, with for each $h \in H$, $\bar{x}_{h}^{\prime}=$ $\left(\bar{x}_{h},\left(\bar{G}_{1, h}, \ldots, \bar{G}_{H, h}\right)\right) \in X_{h}^{\prime}$, then there exists $\bar{G}$ such that $\left(\left(\bar{x}_{h}\right)_{h \in H}, \bar{G}\right)$ is Lindahl-Foley feasible in $\mathcal{E}$.

(c) If $\left(\left(\bar{x}_{h}\right)_{h \in H}, \bar{G}\right)$ is weakly Pareto optimal in $\mathcal{E}$, the corresponding $\left(\bar{x}_{h}^{\prime}\right)_{h \in H}$ is a weak Pareto optimum in $\mathcal{E}^{\prime}$.

(d) If $\left(\left(\bar{x}_{h}\right)_{h \in H}, \bar{G}\right) \in \mathcal{C}(\mathcal{E})$, the corresponding $\left(\bar{x}_{h}^{\prime}\right)_{h \in H}$ belongs to the core $\mathcal{C}\left(\mathcal{E}^{\prime}\right)$.

(e) Let $\varnothing \neq T \subset H \times\{1, \ldots, n\}$. If the pair $\left.\left(\left(x_{h, s}\right)_{(h, s) \in T}, G^{T}\right)\right)$ is $T$-feasible in $\mathcal{E}_{n}$, then the assignment $\left(x_{h, s}^{\prime}\right)_{(h, s) \in T}$ where for each $(h, s) \in T, x_{h, s}^{\prime}=\left(x_{h, s},\left(0, \ldots, \frac{1}{|T(h)|} G^{T}, \ldots, 0\right)\right)$ is $T$-feasible in $\mathcal{E}_{n}^{\prime}$.

Conversely, if $\left(x_{h, s}^{\prime}\right)_{(h, s) \in T}$ is $T$-feasible in $\mathcal{E}_{n}^{\prime}$, with for each $(h, s) \in T$,

$$
x_{h, s}^{\prime}=\left(x_{h, s},\left(G_{1, h, s}, \ldots, G_{h, h, s}, \ldots, G_{H, h, s}\right)\right) \in X_{h, s}^{\prime}=X_{h}^{\prime},
$$


then there exists $G^{T}$ such that $\left(\left(x_{h, s}\right)_{(h, s) \in T}, G^{T}\right)$ is $T$-feasible in $\mathcal{E}_{n}$. Moreover, $G^{T} \geq$ $\sum_{s \in T(h)} G_{h, h, s}, \forall h: T(h) \neq \varnothing$.

(f) Let $\left(\left(\bar{x}_{h}\right)_{h \in H}, \bar{G}\right)$ be Lindahl-Foley feasible in $\mathcal{E}$ and $\left(\bar{x}_{h}^{\prime}\right)_{h \in H}$ be the corresponding feasible allocation in $\mathcal{E}^{\prime}$. If a coalition $T$ blocks in $\mathcal{E}_{n}^{\prime}$ the n-replica of $\left(x_{h}^{\prime}\right)_{h \in H}$, then $T$ blocks in $\mathcal{E}_{n}$ the $n$-replica of $\left(\left(\bar{x}_{h}\right)_{h \in H}, \bar{G}\right)$. Consequently, if $\left(\left(\bar{x}_{h}\right)_{h \in H}, \bar{G}\right) \in \mathcal{C}^{E}(\mathcal{E})$, the corresponding $\left(\bar{x}_{h}^{\prime}\right)_{h \in H}$ is an Edgeworth equilibrium of $\mathcal{E}^{\prime}$.

Proof. To prove a., let us assume that for some $S \subset H$ and for some $\left(y_{f}, y_{f}^{g}\right)_{f \in F} \in \prod_{f \in F} Y_{f}$, one has

$$
\sum_{h \in S} x_{h}=\sum_{h \in S} \omega_{h}+\sum_{h \in S} \sum_{f \in F} \theta_{h, f} y_{f}
$$

and

$$
G^{S}=\sum_{h \in S} \sum_{f \in F} \theta_{h, f} y_{f}^{g}
$$

Then,

$$
\begin{gathered}
\sum_{h \in S} x_{h}^{\prime}=\sum_{h \in S}\left(\left(x_{h},\left(0, \ldots, G^{S}, \ldots 0\right)\right)=\left(\sum_{h \in S} x_{h},\left(G^{S}\right)_{h^{\prime} \in S},(0)_{h^{\prime} \notin S}\right)\right. \\
=\sum_{h \in S}\left(\omega_{h},(0, \ldots, 0)\right)+\left(\sum_{h \in S} \sum_{f \in F} \theta_{h, f} y_{f},\left(\left(\sum_{h \in S} \sum_{f \in F} \theta_{h, f} y_{f}^{g}\right)_{h^{\prime} \in S},(0)_{h^{\prime} \notin S}\right)\right) \\
\in \sum_{h \in S} e_{h}^{\prime}+\sum_{h \in S} \sum_{f \in F} \theta_{h, f} Y_{f}^{\prime},
\end{gathered}
$$

by definition of $Y_{f}^{\prime}$.

Assume conversely that for some $S \subset H$ and for some $\left(y_{f}, y_{f}^{g}\right)_{f \in F} \in \prod_{f \in F} Y_{f}$, one has

$$
\sum_{h \in S} x_{h}^{\prime}=\sum_{h \in S}\left(x_{h},\left(G_{1, h}, \ldots, G_{h, h} \ldots, G_{H, h}\right)\right)=\sum_{h \in S}\left(\omega_{h},(0, \ldots, 0)\right)+\sum_{h \in S} \sum_{f \in F} \theta_{h, f} y_{f}^{\prime}
$$

with $y_{f}^{\prime}=\left(y_{f}, y_{1, f}^{g}, \ldots, y_{H, f}^{g}\right), y_{h, f}^{g} \leq y_{f}^{g}$ for each $h \in H$. Setting $G^{S}=\sum_{h \in S} \sum_{f \in F} \theta_{h, f} y_{f}^{g}$, one sees that the consumption pair $\left(\left(x_{h}\right)_{h \in S}, G^{S}\right)$ is $S$-feasible in $\mathcal{E}$. Moreover, since for every $h^{\prime} \in H$,

$$
\sum_{h \in S} G_{h^{\prime}, h}=\sum_{h \in S} \sum_{f \in F} \theta_{h, f} y_{h^{\prime}, f}^{g} \leq \sum_{h \in S} \sum_{f \in F} \theta_{h, f} y_{f}^{g}=G^{S}
$$

one has a fortiori for every $h^{\prime} \in S, G_{h^{\prime}, h^{\prime}} \leq G^{S}$.

To prove c. and d., consider a feasible allocation $\left(\left(\bar{x}_{h}\right)_{h \in H}, \bar{G}\right)$ in $\mathcal{E}$ and the corresponding allocation $\left(\bar{x}_{h}^{\prime}\right)_{h \in H}$ in $\mathcal{E}^{\prime}$. It suffices to prove that if some coalition $S$ blocks $\left(\bar{x}_{h}^{\prime}\right)_{h \in H}$ in $\mathcal{E}^{\prime}$ then the same coalition blocks $\left(\left(\bar{x}_{h}\right)_{h \in H}, \bar{G}\right)$ in $\mathcal{E}$. Indeed, assume that some $\left(x_{h}^{\prime}\right)_{h \in S} \in \prod_{h \in S} X_{h}^{\prime}$ satisfies for some $\left(y_{f}, y_{f}^{g}\right)_{f \in F} \in \prod_{f \in F} Y_{f}$,

$$
\sum_{h \in S}\left(x_{h},\left(G_{1, h}, \ldots, G_{h, h}, \ldots, G_{H, h}\right)\right)=\sum_{h \in S}\left(\omega_{h},(0, \ldots 0)\right)+\sum_{h \in S} \sum_{f \in F} \theta_{h, f}\left(y_{f},\left(y_{1, f}^{g}, \ldots, y_{H, f}^{g}\right)\right)
$$

with for each $h \in H y_{h, f}^{g} \leq y_{f}^{g}$, and for each $h \in S$,

$$
u_{h}\left(x_{h}, G_{h, h}\right)=u^{\prime}\left(x_{h}^{\prime}\right)>u_{h}^{\prime}\left(\bar{x}_{h}^{\prime}\right)=u_{h}\left(\bar{x}_{h}, \bar{G}\right) .
$$


Letting $G^{S}=\sum_{h \in S} \sum_{f \in F} \theta_{h, f} y_{f}^{g}$, it follows from a. that $\left(\left(x_{h}\right)_{h \in S}, G^{S}\right)$ is $S$-feasible in $\mathcal{E}$. It also follows from a. and the monotonicity of the $u_{h}$ with respect to public goods that for each $h \in S$, $u_{h}\left(x_{h}, G^{S}\right)>u_{h}\left(\bar{x}_{h}, \bar{G}\right)$.

To prove e., according to the definition of replica economies of private ownership production economies with private goods, ${ }^{4}$ recall first that in $\mathcal{E}_{n}^{\prime}$,

$$
\begin{gathered}
X_{h, s}^{\prime}=X_{h}^{\prime}=\left\{x_{h, s}^{\prime} \in L_{+} \times\left(\mathbb{R}_{+}^{K}\right)^{H}: x_{h, s}^{\prime}=\left(x_{h, s},\left(G_{1, h, s}, \ldots, G_{h, h, s}, \ldots, G_{H, h, s}\right)\right\} ;\right. \\
Y_{f, t}^{\prime}=Y_{f}^{\prime}=\left\{\begin{array}{r}
\left.y_{f, t}^{\prime} \in L \times\left(\mathbb{R}^{K}\right)^{H}: \begin{array}{l}
\exists\left(y_{f, t}, y_{f, t}^{g}\right) \in Y_{f}, \\
y_{f, t}^{\prime}=\left(y_{f, t},\left(y_{1, f, t}^{g}, \ldots, y_{H, f, t}^{g}\right)\right), y_{h, f, t} \leq y_{f, t}^{g} \forall h \in H
\end{array}\right\} ; \\
e_{h, s}^{\prime}=e_{h}^{\prime}=\left(\omega_{h},(0, \ldots, 0)\right) ; \\
\theta_{h, s, f, t}=0 \text { if } s \neq t \text { and } \theta_{h, s, f, t}=\theta_{h, f} \text { if } s=t .
\end{array}\right.
\end{gathered}
$$

Assume that $\left(\left(x_{h, s}\right)_{(h, s) \in T}, G^{T}\right)$ is a $T$-feasible pair satisfying (3.1) and (3.2) of Definition 3.5. Then, letting for each $(h, s) \in T, x_{h, s}^{\prime}=\left(x_{h, s},\left(0, \ldots, \frac{1}{|T(h)|} G^{T}, \ldots 0\right)\right)$, one has:

$$
\begin{gathered}
\sum_{(h, s) \in T} x_{h, s}^{\prime}=\left(\sum_{(h, s) \in T} x_{h, s},\left(\left(G^{T}\right)_{\left\{h^{\prime}: T\left(h^{\prime}\right) \neq \varnothing\right\}},(0)_{\left\{h^{\prime}: T\left(h^{\prime}\right)=\varnothing\right\}}\right)\right) \\
=\sum_{h \in H}|T(h)|\left(\omega_{h},(0, \ldots, 0)\right)+\sum_{(h, s) \in T} \sum_{f \in F} \theta_{h, f}\left(y_{f, s},\left(\left(y_{f, s}^{g}\right)_{\left\{h^{\prime}: T\left(h^{\prime}\right) \neq \varnothing\right\}},(0)_{\left\{h^{\prime}: T\left(h^{\prime}\right)=\varnothing\right\}}\right)\right) \\
\in \sum_{h \in H}|T(h)|\left(\omega_{h},(0, \ldots, 0)\right)+\sum_{(h, s) \in T} \sum_{f \in F} \theta_{h, f} Y_{f, s}^{\prime}
\end{gathered}
$$

by definition of $Y_{f, s}^{\prime}$.

Conversely, assume that

$$
\left(x_{h, s}^{\prime}\right)_{(h, s) \in T}=\left(x_{h, s},\left(G_{1, h, s}, \ldots, G_{h, h, s}, \ldots, G_{H, h, s}\right)_{(h, s) \in T} \in \prod_{(h, s) \in T} X_{h, s}^{\prime}\right.
$$

is $T$-feasible in $\mathcal{E}_{n}^{\prime}$, that is,

$$
\sum_{(h, s) \in T} x_{h, s}^{\prime}=\sum_{h \in H}|T(h)|\left(\omega_{h},(0, \ldots, 0)\right)+\sum_{(h, s) \in T} \sum_{f \in F} \theta_{h, f} y_{f, s}^{\prime}
$$

with for each $(f, s)$, for each $h \in H$,

$$
y_{f, s}^{\prime}=\left(y_{f, s},\left(y_{1, f, s}^{g}, \ldots, y_{H, f, s}^{g}\right)\right), \quad y_{h, f, s}^{g} \leq y_{f, s}^{g}, \quad\left(y_{f, s}, y_{f, s}^{g}\right) \in Y_{f} .
$$

For each $h^{\prime}$ and each $h: T(h) \neq \varnothing$ one has

$$
\sum_{s \in T(h)} G_{h^{\prime}, h, s} \leq \sum_{(h, s) \in T} G_{h^{\prime}, h, s}=\sum_{(h, s) \in T} \sum_{f \in F} \theta_{h, f} y_{h^{\prime}, f, s} \leq \sum_{(h, s) \in T} \sum_{f \in F} \theta_{h, f} y_{f, s} .
$$

Define $G^{T}=\sum_{(h, s) \in T} \sum_{f \in F} \theta_{h, f} y_{f, s}$. The pair $\left(\left(x_{h, s}\right)_{(h, s) \in T}, G^{T}\right)$ is $T$-feasible in $\mathcal{E}_{n}$. Moreover, for each $h: T(h) \neq \varnothing, \sum_{s \in T(h)} G_{h, h, s} \leq G^{T}$.

To prove f., consider now a feasible allocation $\left(\left(\bar{x}_{h}\right)_{h \in H}, \bar{G}\right)$ in $\mathcal{E}$, the corresponding allocation $\left(\bar{x}_{h}^{\prime}\right)_{h \in H}$ in $\mathcal{E}^{\prime}$ and assume that the coalition $T \subset H \times\{1, \ldots, n\}$ blocks the $n$-replica of $\left(\bar{x}_{h}^{\prime}\right)_{h \in H}$ with some $\left(x_{h, s}^{\prime}\right)_{(h, s) \in T} \in \prod_{(h, s) \in T} X_{h, s}^{\prime}$. With the previous definitions and notations, the pair

${ }^{4}$ See, for example, Aliprantis, Brown and Burkinshaw (1987). 
$\left(\left(x_{h, s}\right)_{(h, s) \in T}, G^{T}\right)$ is $T$-feasible.

On the other hand, one has for each $(h, s) \in T, u_{h}\left(x_{h, s}, G_{h, h, s}\right)>u_{h}\left(\bar{x}_{h}, \bar{G}\right)$. It follows from the quasiconcavity of utility functions that for each $h: T(h) \neq \varnothing$,

$$
u_{h}\left(\frac{1}{|T(h)|} \sum_{s \in T(h)} x_{h, s}, \frac{1}{|T(h)|} \sum_{s \in T(h)} G_{h, h, s}\right)>u_{h}\left(\bar{x}_{h}, \bar{G}\right)
$$

and from e. and the monotonicity of $u_{h}$ with respect to public goods that

$$
u_{h}\left(\frac{1}{|T(h)|} \sum_{s \in T(h)} x_{h, s}, \frac{1}{|T(h)|} G^{T}\right)>u_{h}\left(\bar{x}_{h}, \bar{G}\right) .
$$

For $h: T(h) \neq \varnothing$, set $\widetilde{x}_{h}=\frac{1}{|T(h)|} \sum_{\{s \in T(h)\}} x_{h, s}$. This proves that the coalition $T$ blocks in $\mathcal{E}_{n}$ the $n$-replica of $\left(\left(\bar{x}_{h}\right)_{h \in H}, \bar{G}\right)$ with the $T$-feasible pair $\left(\left(\widetilde{x}_{h}\right)_{(h, s) \in T}, G^{T}\right)$. The last assertion of $\mathrm{f}$. is now obvious.

In the sequel, we start with an Edgeworth equilibrium $\left(\left(\bar{x}_{h}\right)_{h \in H}, \bar{G}\right)$ as obtained in Theorem 4.2 and show how to decentralize it as a Lindahl-Foley equilibrium of $\mathcal{E}$ with prices in $L^{\prime} \times\left(\mathbb{R}^{K}\right)^{H}$. More precisely, let for each $f \in F,\left(\bar{y}_{f}, \bar{y}_{f}^{g}\right) \in Y_{f}$ be such that

$$
\sum_{h \in H} \bar{x}_{h}=\sum_{h \in H} \omega_{h}+\sum_{f \in F} \bar{y}_{f}
$$

and

$$
\bar{G}=\sum_{f \in F} \bar{y}_{f}^{g} .
$$

With the allocation $\left(\left(\left(\bar{x}_{h}\right)_{h \in H}, \bar{G}\right),\left(\bar{y}_{f}, \bar{y}_{f}^{g}\right)_{f \in F}\right)$, we will associate a nonzero price vector

$$
\left(\bar{p},\left(\bar{p}_{h}^{g}\right)_{h \in H}\right) \in L^{\prime} \times\left(\mathbb{R}_{+}^{K}\right)^{H}
$$

such that for each $h \in H$, for each $\left(x_{h}, G\right) \in L_{+} \times \mathbb{R}_{+}^{K}$, for each $f \in F$, and for every $\left(y_{f}, y_{f}^{g}\right) \in Y_{f}$,

$$
\begin{gathered}
\bar{p} \cdot \bar{x}_{h}+\bar{p}_{h}^{g} \cdot \bar{G}=\bar{p} \cdot \omega_{h}+\sum_{f \in F} \theta_{h, f}\left(\bar{p} \cdot \bar{y}_{f}+\left(\sum_{h \in H} \bar{p}_{h}^{g}\right) \cdot \bar{y}_{f}^{g}\right), \\
u_{h}\left(x_{h}, G\right)>u_{h}\left(\bar{x}_{h}, \bar{G}\right) \Longrightarrow \bar{p} \cdot x_{h}+\bar{p}_{h}^{g} \cdot G \geq \bar{p} \cdot \bar{x}_{h}+\bar{p}_{h}^{g} \cdot \bar{G}, \\
\bar{p} \cdot y_{f}+\left(\sum_{h \in H} \bar{p}_{h}^{g}\right) y_{f}^{g} \leq \bar{p} \cdot \bar{y}_{f}+\left(\sum_{h \in H} \bar{p}_{h}^{g}\right) \bar{y}_{f}^{g} .
\end{gathered}
$$

Such a $\left(\left(\left(\bar{x}_{h}\right)_{h \in H}, \bar{G}\right),\left(\bar{y}_{f}, \bar{y}_{f}^{g}\right)_{f \in F},\left(\bar{p},\left(\bar{p}_{h}^{g}\right)_{h \in H}\right)\right)$ will be called Lindahl-Foley quasiequilibrium. If for some $h \in H, u_{h}\left(x_{h}, G\right)>u_{h}\left(\bar{x}_{h}, \bar{G}\right)$ actually implies $\bar{p} \cdot x_{h}+\bar{p}_{h}^{g} \cdot G>\bar{p} \cdot \bar{x}_{h}+\bar{p}_{h}^{g} \cdot \bar{G}$, this quasiequilibrium will be called non-trivial.

From now on, we set on $\mathcal{E}$ the following additional assumptions:

A4: If $\left(\left(x_{h}\right)_{h \in H}, G\right)$ is a $H$-feasible and individually rational pair in $\mathcal{E}$, each utility function $u_{h}$ is lower semicontinuous at $\left(x_{h}, G\right)$.

A5: If $\left(\left(x_{h}\right)_{h \in H}, G\right)$ is a $H$-feasible and individually rational pair in $\mathcal{E}$, then for each $h \in H$ there exists $x_{h}^{\prime} \in L_{+}$such that $u_{h}\left(x_{h}+\lambda\left(x_{h}^{\prime}-x_{h}\right), G\right)>u_{h}\left(x_{h}, G\right)$ for every $\lambda: 0<\lambda \leq 1$. 
A.6: If $\left(\left(x_{h}\right)_{h \in H}, G\right)$ is a $H$-feasible and individually rational pair in $\mathcal{E}$, then there exists $h \in H$ and $G_{h} \in \mathbb{R}_{+}^{K}$ such that $u_{h}\left(x_{h}, G_{h}\right)>u_{h}\left(x_{h}, G\right)$.

5.2. Decentralization in a finite dimensional setting. In this subsection, $L$ is some finite dimensional Euclidean space equipped with its Euclidean topology $\tau$. Its topological dual $L^{\prime}$ is as usual identified with $L$.

Proposition 5.2. Let $\left(\left(\bar{x}_{h}\right)_{h \in H}, \bar{G}\right)$ be an Edgeworth equilibrium consumption allocation and let $\left(\bar{y}_{f}, \bar{y}_{f}^{g}\right)_{f \in F}$ be the production allocation satisfying (5.1) and (5.2).

(a) There exists $\left(\bar{p},\left(\bar{p}_{h}^{g}\right)_{h \in H}\right) \in L^{\prime} \times\left(\mathbb{R}_{+}^{K}\right)^{H}$ such that $\left(\left(\left(\bar{x}_{h}\right)_{h \in H}, \bar{G}\right),\left(\bar{y}_{f}, \bar{y}_{f}^{g}\right)_{f \in F},\left(\bar{p},\left(\bar{p}_{h}^{g}\right)_{h \in H}\right)\right)$ is a Lindahl-Foley quasiequilibrium.

(b) The quasiequilibrium is nontrivial provided that $\left.(\omega, 0) \in \operatorname{int}\left(\left(L_{+} \times \mathbb{R}_{+}^{K}\right)-Y\right)\right)$. In this case, $\bar{p} \neq 0$.

(c) If the quasiequilibrium is an equilibrium, then $\left(\bar{p}_{h}^{g}\right)_{h \in H} \neq 0$ and consequently $\sum_{h \in H} p_{h}^{g} \neq 0$.

Proof. As shown in Proposition 5.1, the allocation $\left(\bar{x}_{h}^{\prime}\right)_{h \in H}=\left(\bar{x}_{h},(0, \ldots, \bar{G}, \ldots, 0)\right)_{h \in H}$ satisfies

$$
\begin{gathered}
\sum_{h \in H}\left(\left(\bar{x}_{h},(0, \ldots, \bar{G}, \ldots 0)\right)=\sum_{h \in H} \bar{x}_{h}^{\prime}=\sum_{h \in H} e_{h}^{\prime}+\sum_{f \in F} \bar{y}_{f}^{\prime}\right. \\
=\sum_{h \in H}\left(\omega_{h},(0, \ldots, 0)\right)+\left(\sum_{f \in F} \bar{y}_{f},\left(\sum_{f \in F} \bar{y}_{f}^{g}, \ldots, \sum_{f \in F} \bar{y}_{f}^{g}, \ldots, \sum_{f \in F} \bar{y}_{f}^{g}\right)\right)
\end{gathered}
$$

and is an Edgeworth equilibrium consumption allocation of $\mathcal{E}^{\prime}$ that we will decentralize with a nonzero price as a quasiequilibrium allocation of $\mathcal{E}^{\prime}$.

From Assumptions A4 and A5, we easily deduce local non-satiation of preferences in $\mathcal{E}^{\prime}$ at each component $\left(\bar{x}_{h},(0, \ldots, \bar{G}, \ldots, 0)\right)$ and openness in each $X_{h}^{\prime}=L_{+} \times\left(\mathbb{R}_{+}^{K}\right)^{H}$ of preferred sets

$$
P_{h}\left(\left(\bar{x}_{h},(0, \ldots, \bar{G}, \ldots, 0)\right)=\left\{x_{h}^{\prime}=\left(x_{h},\left(G_{1, h}, \ldots, G_{H, h}\right)\right) \in X_{h}^{\prime}: u_{h}\left(x_{h}, G_{h, h}\right)>u_{h}\left(\bar{x}_{h}, \bar{G}\right)\right\}\right.
$$

for the topology $\tau \times \tau_{\mathbb{R}^{K}} \times \ldots \times \tau_{\mathbb{R}^{K}}$. It then follows from the classical result of decentralization in private ownership economies with private goods that there exists $\bar{\pi}=\left(\bar{p},\left(\bar{p}_{1}^{g}, \ldots, \bar{p}_{H}^{g}\right)\right) \neq 0$ such that

$$
\begin{gathered}
\text { for each } h \in H, \bar{\pi} \cdot \bar{x}_{h}^{\prime}=\bar{\pi} \cdot e_{h}^{\prime}+\sum_{f \in F} \theta_{h, f} \bar{\pi} \cdot \bar{y}_{f}^{\prime}, \\
{\left[x_{h}^{\prime} \in X_{h}^{\prime} \text { and } u_{h}\left(x_{h}, G_{h, h}\right)>u_{h}\left(\bar{x}_{h}, \bar{G}\right)\right] \Longrightarrow \bar{\pi} \cdot x_{h}^{\prime} \geq \bar{\pi} \cdot e_{h}^{\prime}+\sum_{f \in F} \theta_{h, f} \bar{\pi} \cdot \bar{y}_{f}^{\prime},}
\end{gathered}
$$

for each $f \in F$ and for every $y_{f}^{\prime} \in Y_{f}^{\prime}, \bar{\pi} \cdot y_{f}^{\prime} \leq \bar{\pi} \cdot \bar{y}_{f}^{\prime}$.

In other words, $\left(\left(\bar{x}_{h}^{\prime}\right)_{h \in H},\left(\bar{y}_{f}^{\prime}\right)_{f \in F}, \bar{\pi}\right)$ is a quasiequilibrium of $\mathcal{E}^{\prime}$ with a nonzero quasiequilibrium price.

The previous relations imply:

$$
\begin{aligned}
& \text { for each } h \in H, \bar{p} \cdot \bar{x}_{h}+\bar{p}_{h}^{g} \cdot \bar{G}=\bar{p} \cdot \omega_{h}+\sum_{f \in F} \theta_{h, f}\left(\bar{p} \cdot \bar{y}_{f}+\left(\sum_{h \in H} \bar{p}_{h}^{g}\right) \cdot \bar{y}_{f}^{g}\right), \\
& {\left[\left(x_{h}, G\right) \in L_{+} \times \mathbb{R}_{+}^{K} \text { and } u_{h}\left(x_{h}, G\right)>u_{h}\left(\bar{x}_{h}, \bar{G}\right)\right] \Longrightarrow \bar{p} \cdot x_{h}+\bar{p}_{h}^{g} \cdot G \geq \bar{p} \cdot \bar{x}_{h}+\bar{p}_{h}^{g} \cdot \bar{G},}
\end{aligned}
$$




$$
\left[\left(y_{f}, y_{f}^{g}\right) \in Y_{f} \text { and } y_{h, f}^{g} \leq y_{f}^{g} \forall h \in H\right] \Longrightarrow \bar{p} \cdot y_{f}+\sum_{h \in H} \bar{p}_{h}^{g} \cdot y_{h, f}^{g} \leq \bar{p} \cdot \bar{y}_{f}+\left(\sum_{h \in H} \bar{p}_{h}^{g}\right) \cdot \bar{y}_{f}^{g} .
$$

In particular, for each $f \in F$ and for every $\left(y_{f}, y_{f}^{g}\right) \in Y_{f}$,

$$
\bar{p} \cdot y_{f}+\left(\sum_{h \in H} \bar{p}_{h}^{g}\right) y_{f}^{g} \leq \bar{p} \cdot \bar{y}_{f}+\left(\sum_{h \in H} \bar{p}_{h}^{g}\right) \bar{y}_{f}^{g} .
$$

From (5.11), we deduce that for each $h \in H, \bar{p}_{h}^{g} \geq 0$, and the proof of a. is complete.

To prove b., assume that $\left.(\omega, 0) \in \operatorname{int}\left(\left(L_{+} \times \mathbb{R}_{+}^{K}\right)-Y\right)\right)$. Since $\left(\bar{p},\left(\bar{p}_{h}^{g}\right)_{h \in H}\right) \neq 0$, there is some $(u, v) \in L \times \mathbb{R}^{K}$ such that $\left(\bar{p}, \sum_{h \in H} \bar{p}_{h}^{g}\right) \cdot(u, v)<0$ and $(\omega, 0)+(u, v) \in\left(L_{+} \times \mathbb{R}_{+}^{K}\right)-Y$. Let $\delta=$ $\left(\bar{p}, \sum_{h \in H} \bar{p}_{h}^{g}\right) \cdot(u, v)$. One can write for some $\left(x_{h}\right)_{h \in H} \in\left(L_{+}\right)^{H}, G \in \mathbb{R}_{+}^{K},\left(y_{f}, y_{f}^{g}\right)_{f \in F} \in \prod_{f \in F} Y_{f}$

$$
(\omega, 0)+(u, v)=\left(\sum_{h \in H} x_{h}, G\right)-\sum_{f \in F}\left(y_{f}, y_{f}^{g}\right) .
$$

One deduces:

$$
\bar{p} \cdot \sum_{h \in H} x_{h}+\left(\sum_{h \in H} \bar{p}_{h}^{g}\right) \cdot G-\sum_{f \in F}\left(\bar{p}, \sum_{h \in H} \bar{p}_{h}^{g}\right) \cdot\left(y_{f}, y_{f}^{g}\right)=\bar{p} \cdot \omega+\delta
$$

that is

$$
\begin{aligned}
& \sum_{h \in H}\left(\bar{p} \cdot x_{h}+\bar{p}_{h}^{g} \cdot G\right)<\bar{p} \cdot \sum_{h \in H} \omega_{h}+\sum_{f \in F}\left(\bar{p}, \sum_{h \in H} \bar{p}_{h}^{g}\right) \cdot\left(y_{f}, y_{f}^{g}\right) \\
& \leq \bar{p} \cdot \sum_{h \in H} \omega_{h}+\sum_{f \in F}\left(\bar{p}, \sum_{h \in H} \bar{p}_{h}^{g}\right) \cdot\left(\bar{y}_{f}, \bar{y}_{f}^{g}\right)=\sum_{h \in H}\left(\bar{p} \cdot \bar{x}_{h}+\bar{p}_{h}^{g} \cdot \bar{G}\right),
\end{aligned}
$$

the last equality being a consequence of the feasibility of the Edgeworth equilibrium consumption allocation $\left(\left(\bar{x}_{h}\right)_{h \in H}, \bar{G}\right)$.

It thus follows that for some $h \in H, \bar{p} \cdot x_{h}+\bar{p}_{h}^{g} \cdot G<\bar{p} \cdot \bar{x}_{h}+\bar{p}_{h}^{g} \cdot \bar{G}$. Some consumer $h \in H$ can satisfy his budget constraint with a strict inequality. As usual, since in view of Assumption A4 the utility function $u_{h}$ is lower semicontinuous at $\left(\bar{x}_{h}, \bar{G}\right)$, consumer $h$ is utility maximizing at this point under his budget constraint, and the quasiequilibrium is non-trivial.

Since the quasiequilibrium is non-trivial, using (5.10), it follows from Assumption A5 that for some $h \in H$ and for some $x_{h} \in L_{+}$

which proves that $\bar{p} \neq 0$.

$$
\bar{p} \cdot x_{h}>\bar{p} \cdot \bar{x}_{h},
$$

To prove c., assume finally that the quasiequilibrium is an equilibrium. Using (5.10), it then follows from Assumption A.6 that for some $h \in H$ and for some $G_{h} \in \mathbb{R}_{+}^{K}$,

$$
\bar{p}_{h}^{g} \cdot G_{h}>\bar{p}_{h}^{g} \cdot \bar{G},
$$

which proves that $\bar{p}_{h}^{g} \neq 0$.

Remark 5.2. The condition for non-triviality

NT: $(\omega, 0) \in \operatorname{int}\left(\left(L_{+} \times \mathbb{R}_{+}^{K}\right)-Y\right)$

is satisfied for example under the following mild conditions that the total initial endowment in private goods be strictly positive and that each public good be producible:

- $\omega \gg 0$

- there exists some $\left(y, y^{g}\right) \in Y$ with $y^{g} \gg 0$. 
Remark 5.3. Several irreducibility conditions guarantee that a non-trivial quasiequilibrium is an equilibrium.

A very simple condition, inspired by Arrow and Hahn (1971), is the following:

IR: For any non-trivial partition $\left\{H_{1}, H_{2}\right\}$ of the set $H$ of consumers and for any feasible allocation $\left(\left(\left(x_{h}\right)_{h \in H}, G\right),\left(y_{f}, y_{f}^{g}\right)_{f \in F}\right)$ of $\mathcal{E}$, there exist $\left(\left(\widetilde{x}_{h}\right)_{h \in H}, \widetilde{G}\right) \in\left(L_{+}\right)^{H} \times \mathbb{R}_{+}^{K}$ and $\omega^{\prime} \in L_{+}$such that

- $u_{h}\left(\widetilde{x}_{h}, \widetilde{G}\right) \geq u_{h}\left(x_{h}, G\right) \forall h \in H_{1}$, with a strict inequality for at least one $h$ of $H_{1}$;

- $\left(\sum_{h \in H} \widetilde{x}_{h}, \widetilde{G}\right) \in\left\{\omega^{\prime}\right\}+\sum_{f \in F} Y_{f}$ with, for each coordinate $i, \omega^{i}>\omega^{i} \Longrightarrow \sum_{h \in H_{2}} \omega_{h}^{i}>$ 0 .

We leave the reader to verify that the non-trivial quasiequilibrium is then an equilibrium.

The obvious interpretation of this condition is that for any partition $\left\{H_{1}, H_{2}\right\}$ of the set of consumers into two nonempty subgroups and for each feasible allocation the group $H_{1}$ may be moved to a preferred position, feasible with a new vector of total resources in private goods, by increasing the total resources of commodities which can be supplied in positive amount by the group $\mathrm{H}_{2}$.

Non-triviality and irreducibility conditions are adapted from similar conditions in Chapter 2 of Florenzano (2003).

A by-product of Proposition 5.2 is the following Lindahl-Foley equilibrium existence theorem:

Theorem 5.4. Under the assumptions A1-A6, NT, and IR, the economy $\mathcal{E}$ has a Lindahl-Foley equilibrium $\left(\left(\left(\bar{x}_{h}\right)_{h \in H}, \bar{G}\right),\left(\bar{y}_{f}, \bar{y}_{f}^{g}\right)_{f \in F},\left(\bar{p},\left(\bar{p}_{h}^{g}\right)_{h \in H}\right)\right)$ with a private goods price vector $\bar{p} \neq 0$ and positive personalized price vectors for public goods, $\bar{p}_{h}^{g} \in \mathbb{R}_{+}^{K}, h \in H$, not all equal to zero.

5.3. Decentralization in an infinite dimensional setting. In this subsection, as usual since Mas-Colell and Richard (1991) in an infinite dimensional setting, we make on the dual pair $\left\langle L, L^{\prime}\right\rangle$ the following structural assumption:

SA: $L$ is a linear vector lattice (or Riesz space) equipped with a Hausdorff locally convex linear topology $\tau$ such that

- The positive cone $L_{+}$is closed for the $\tau$-topology of $L$;

- $L^{\prime}=(L, \tau)^{\prime}$, the topological dual of $L$ for the topology $\tau$ (i.e. $\tau$ is compatible with the duality $\left.\left\langle L, L^{\prime}\right\rangle\right)$ and $L^{\prime}$ is a vector sublattice of the order dual $L^{\sim}$ of $L .^{5}$

It is worth noticing that it follows from Assumption SA that the commodity-price duality $\langle L \times$ $\left.\left(\mathbb{R}^{K}\right)^{H}, L^{\prime} \times\left(\mathbb{R}^{K}\right)^{H}\right\rangle$ of the enlarged economy $\mathcal{E}^{\prime}$ associated to $\mathcal{E}$ satisfies the same type of assumption.

The decentralization with prices of an Edgeworth equilibrium of $\mathcal{E}$ will be obtained under the following properness assumptions adapted from Tourky $(1998,1999)$.

A7: If $\left(\left(x_{h}\right)_{h \in H}, G\right)$ is a $H$-feasible and individually rational pair in $\mathcal{E}$, then for each $h \in H$ there exists a convex set $\widehat{P}_{h}\left(x_{h}, G\right) \subset L \times \mathbb{R}^{K}$ such that

- $\widehat{P}_{h}\left(x_{h}, G\right) \cap\left(L_{+} \times \mathbb{R}_{+}^{K}\right)=\left\{\left(\widetilde{x}_{h}, \widetilde{G}\right) \in\left(L_{+} \times \mathbb{R}_{+}^{K}\right): u_{h}\left(\widetilde{x}_{h}, \widetilde{G}\right)>u_{h}\left(x_{h}, G\right)\right\}$;

- $\left(x_{h}, G\right)+(\omega, 0)$ is a $\tau$-interior point of $\widehat{P}_{h}\left(x_{h}, G\right)$.

\footnotetext{
${ }^{5} L^{\sim}$ is by definition the vector space of all linear functionals $f$ on $L$ such that the image by $f$ of any order interval of $L$ is an order bounded subset of $\mathbb{R}$.
} 
When Assumption A7 is satisfied, we say that preferences are $(\omega, 0)$-proper at every component of a $H$-feasible and individually rational pair in $\mathcal{E}$.

A8: If $\left(\left(x_{h}\right)_{h \in H}, G\right)$ is a $H$-feasible and individually rational pair in $\mathcal{E}$ and if $\left(\sum_{h \in H}\left(x_{h}-\right.\right.$ $\left.\left.\omega_{h}\right), G\right)=\sum_{f \in F}\left(y_{f}, y_{f}^{g}\right)$, then for each $f \in F$ there exist a convex set $\widehat{Y}_{f}\left(y_{f}\right) \subset L \times \mathbb{R}^{K}$ and a lattice $Z_{y_{f}} \subset L \times \mathbb{R}^{K}$ such that

- $\widehat{Y}_{f}\left(y_{f}\right) \cap Z_{y_{f}}=Y_{f}$;

- $\left(y_{f}, y_{f}^{g}\right)-(\omega, 0)$ is a $\tau$-interior point of $\widehat{Y}_{f}\left(y_{f}\right)$;

- $(0,0) \in Z_{y_{f}}$, and $Z_{y_{f}}-\left(L_{+} \times \mathbb{R}_{+}^{K}\right) \subset Z_{y_{f}}$.

When Assumption $\mathbf{A} 8$ is satisfied, we say that each production set is $(\omega, 0)$-proper at the corresponding component of any $H$-feasible and individually rational allocation $\left.\left(\left(x_{h}\right)_{h \in H}, G\right),\left(y_{f}, y_{f}^{g}\right)_{f \in F}\right)$.

Proposition 5.3. Assume SA, A4-A8 and that $\omega>0$. Let $\left(\left(\bar{x}_{h}\right)_{h \in H}, \bar{G}\right)$ be an Edgeworth equilibrium consumption allocation and let $\left(\bar{y}_{f}, \bar{y}_{f}^{g}\right)_{f \in F}$ be the production allocation satisfying (5.1) and (5.2). Then,

(a) There exists $\left(\bar{p},\left(\bar{p}_{h}^{g}\right)_{h \in H}\right) \in L^{\prime} \times\left(\mathbb{R}_{+}^{K}\right)^{H}$ such that $\bar{p} \cdot \omega>0$ and

$$
\left(\left(\left(\bar{x}_{h}\right)_{h \in H}, \bar{G}\right),\left(\bar{y}_{f}, \bar{y}_{f}^{g}\right)_{f \in F},\left(\bar{p},\left(\bar{p}_{h}^{g}\right)_{h \in H}\right)\right)
$$

is a Lindahl-Foley quasiequilibrium.

(b) If inaction is possible for consumers and producers, the quasiequilibrium is nontrivial.

(c) If the quasiequilibrium is an equilibrium, then $\left(\bar{p}_{h}^{g}\right)_{h \in H} \neq 0$ and consequently $\sum_{h \in H} p_{h}^{g} \neq 0$.

Proof. Recall that in $\mathcal{E}^{\prime}$ consumption and production sets are defined by

$$
\begin{gathered}
X_{h}^{\prime}=\left\{x_{h}^{\prime} \in L_{+} \times\left(\mathbb{R}_{+}^{K}\right)^{H}: x_{h}^{\prime}=\left(x_{h},\left(G_{1, h}, \ldots, G_{H, h}\right)\right)\right\}, \\
Y_{f}^{\prime}=\left\{y_{f}^{\prime} \in L \times\left(\mathbb{R}^{K}\right)^{H}: \exists\left(y_{f}, y_{f}^{g}\right) \in Y_{f}, y_{f}^{\prime}=\left(y_{f},\left(y_{1, f}^{g}, \ldots, y_{H, f}^{g}\right)\right), y_{h, f} \leq y_{f}^{g} \forall h \in H\right\},
\end{gathered}
$$

and that for $x_{h}^{\prime}=\left(x_{h},\left(G_{1, h}, \ldots, G_{H, h}\right)\right) \in X_{h}^{\prime}, u_{h}^{\prime}\left(x_{h}^{\prime}\right)=u_{h}\left(x_{h}, G_{h, h}\right)$, defining the preferred sets

$$
P_{h}^{\prime}\left(x_{h}^{\prime}\right):=\left\{\widetilde{x}^{\prime} \in X_{h}^{\prime}: u_{h}\left(\widetilde{x}_{h}, \widetilde{G}_{h, h}\right)>u_{h}\left(x_{h}, G_{h, h}\right)\right\} .
$$

As shown in the proof of Proposition 5.2, the allocation $\left(\bar{x}_{h}^{\prime}\right)_{h \in H}=\left(\bar{x}_{h},(0, \ldots, \bar{G}, \ldots, 0)\right)_{h \in H}$ satisfies

$$
\begin{gathered}
\sum_{h \in H}\left(\left(\bar{x}_{h},(0, \ldots, \bar{G}, \ldots 0)\right)=\sum_{h \in H} \bar{x}_{h}^{\prime}=\sum_{h \in H} e_{h}^{\prime}+\sum_{f \in F} \bar{y}_{f}^{\prime}\right. \\
=\sum_{h \in H}\left(\omega_{h},(0, \ldots, 0)\right)+\left(\sum_{f \in F} \bar{y}_{f},\left(\sum_{f \in F} \bar{y}_{f}^{g}, \ldots, \sum_{f \in F} \bar{y}_{f}^{g}, \ldots, \sum_{f \in F} \bar{y}_{f}^{g}\right)\right)
\end{gathered}
$$

and is an Edgeworth equilibrium consumption allocation of $\mathcal{E}^{\prime}$, actually, in view of Assumption A4, an element of its fuzzy core. Moreover, we deduce from Assumption A5 local non-satiation of preferences in $\mathcal{E}^{\prime}$ at each component $\left(\bar{x}_{h},(0, \ldots, \bar{G}, \ldots, 0)\right)$.

We first prove that for each $h \in H$, there is a convex set $\widehat{P}_{h}^{\prime}\left(\bar{x}_{h}^{\prime}\right)$ such that

- $\widehat{P}_{h}^{\prime}\left(\bar{x}_{h}^{\prime}\right) \cap\left(L_{+} \times\left(\mathbb{R}_{+}^{K}\right)^{H}\right)=P_{h}^{\prime}\left(\bar{x}_{h}^{\prime}\right)$;

- $\bar{x}_{h}^{\prime}+(\omega,(0, \ldots, 0))$ is a $\tau \times\left(\tau_{\mathbb{R}^{K}}\right)^{H}$ - interior point of $\widehat{P}_{h}^{\prime}\left(\bar{x}_{h}^{\prime}\right)$. 
In other words, we prove that each preference $P_{h}^{\prime}$ is $(\omega,(0, \ldots, 0))$-proper at $\bar{x}_{h}^{\prime}=\left(\bar{x}_{h},(0, \ldots, \bar{G}, \ldots, 0)\right){ }^{6}$ To see this, define

$$
\widehat{P}_{h}^{\prime}\left(\bar{x}_{h}^{\prime}\right)=\left\{\left(x_{h},\left(G_{1, h}, \ldots, G_{H, h}\right)\right) \in L \times\left(\mathbb{R}^{K}\right)^{H}:\left(x_{h}, G_{h, h}\right) \in \widehat{P}_{h}\left(\bar{x}_{h}, \bar{G}\right)\right\} .
$$

Both above conditions follow immediately from A.7.

We next prove that for each $f \in F$, there are a convex set $\widehat{Y}_{f}^{\prime}\left(\bar{y}_{f}^{\prime}\right) \subset L \times\left(\mathbb{R}^{K}\right)^{H}$ and a lattice $Z_{\bar{y}_{f}^{\prime}}^{\prime} \subset L \times\left(\mathbb{R}^{K}\right)^{H}$ such that

- $\widehat{Y}_{f}^{\prime}\left(\bar{y}_{f}^{\prime}\right) \cap Z_{\bar{y}_{f}^{\prime}}^{\prime}=Y_{f}^{\prime}$;

- $\bar{y}_{f}^{\prime}-(\omega,(0, \ldots, 0))$ is a $\tau \times\left(\tau_{\mathbb{R}^{K}}\right)^{H}$ - interior point of $\widehat{Y}_{f}^{\prime}\left(\bar{y}_{f}^{\prime}\right)$;

- $(0,(0, \ldots 0)) \in Z_{\bar{y}_{f}^{\prime}}^{\prime}$, and $Z_{\bar{y}_{f}^{\prime}}^{\prime}-L_{+} \times\left(\mathbb{R}_{+}^{K}\right)^{H} \subset Z_{\bar{y}_{f}^{\prime}}^{\prime}$.

In other words, we prove that each production set $Y_{f}^{\prime}$ is $(\omega,(0, \ldots, 0))$-proper at $\bar{y}_{f}^{\prime}=\left(\bar{y}_{f},\left(\bar{y}_{f}^{g}, \ldots, \bar{y}_{f}^{g}\right)\right) .^{7}$ To see this, define

$$
\begin{gathered}
\widehat{Y}_{f}^{\prime}\left(\bar{y}_{f}^{\prime}\right)=\left\{\left(y_{f},\left(y_{1, f}^{g}, \ldots, y_{H, f}^{g}\right)\right) \in L \times\left(\mathbb{R}^{K}\right)^{H}:\left(y_{f}, y_{f}^{g}\right) \in \widehat{Y}_{f} \text { and } y_{h, f}^{g} \leq y_{f}^{g} \forall h \in H\right\} ; \\
Z_{\bar{y}_{f}^{\prime}}^{\prime}=\left\{\left(y_{f},\left(y_{1, f}^{g}, \ldots, y_{H, f}^{g}\right)\right) \in L \times\left(\mathbb{R}^{K}\right)^{H}:\left(y_{f}, y_{f}^{g}\right) \in Z_{\bar{y}_{f}^{\prime}} \forall y_{f}^{g} \geq \sup _{h \in H} y_{h, f}^{g}\right\} .
\end{gathered}
$$

From the previous definitions and Assumption A.8, it follows that

$$
\widehat{Y}_{f}^{\prime}\left(\bar{y}_{f}^{\prime}\right) \cap Z_{\bar{y}_{f}^{\prime}}^{\prime}=\left\{\left(y_{f},\left(y_{1, f}^{g}, \ldots, y_{H, f}^{g}\right)\right) \in L \times\left(\mathbb{R}^{K}\right)^{H}:\left(y_{f},, y_{f}^{g}\right) \in \widehat{Y}_{f}\left(\bar{y}_{f}\right) \cap Z_{\bar{y}_{f}}=Y_{f}\right\}=Y_{f}^{\prime} .
$$

It is also easily verified that $\bar{y}_{f}^{\prime}-(\omega,(0, \ldots, 0))$ is a $\tau \times\left(\tau_{\mathbb{R}^{K}}\right)^{H}$ - interior point of $\widehat{Y}_{f}^{\prime}\left(\bar{y}_{f}^{\prime}\right)$, and that $Z_{\bar{y}_{f}^{\prime}}^{\prime}$ is a lattice comprehensive and containing the origin.

Applying Proposition 5.3.6 of Florenzano (2003), there exists $\bar{\pi}=\left(\bar{p},\left(\bar{p}_{1}^{g}, \ldots, \bar{p}_{H}^{g}\right)\right) \in L^{\prime} \times$ $\left(\mathbb{R}^{K}\right)^{H}$ such that $\bar{\pi} \cdot(\omega,(0, \ldots, 0))=\bar{p} \cdot \omega>0$ and $\left(\left(\bar{x}_{h}^{\prime}\right)_{h \in H},\left(\bar{y}_{f}^{\prime}\right)_{f \in F},\left(\bar{p},\left(\bar{p}_{1}^{g}, \ldots, \bar{p}_{H}^{g}\right)\right)\right)$ is a quasiequilibrium of $\mathcal{E}$. The rest of the proof of a. is as in the proof of Proposition 5.2. The assertion $\mathrm{b}$. follows from the relation $\bar{p} \cdot \omega>0$. The proof of $\mathrm{c}$. is identical.

Remark 5.5. An infinite dimensional equivalent of the finite dimensional irreducibility assumption is

IR': For any non-trivial partition $\left\{H_{1}, H_{2}\right\}$ of the set $H$ of consumers and for any feasible allocation $\left(\left(\left(x_{h}\right)_{h \in H}, G\right),\left(y_{f}, y_{f}^{g}\right)_{f \in F}\right)$ of $\mathcal{E}$, there exist $\left(\left(\widetilde{x}_{h}\right)_{h \in H}, \widetilde{G}\right) \in\left(L_{+}\right)^{H} \times \mathbb{R}_{+}^{K}$ and $\omega^{\prime} \in L_{+}$such that

- $u_{h}\left(\widetilde{x}_{h}, \widetilde{G}\right) \geq u_{h}\left(x_{h}, G\right) \forall h \in H_{1}$, with a strict inequality for at least one $h$ of $H_{1}$;

- $\left(\sum_{h \in H} \widetilde{x}_{h}, \widetilde{G}\right) \in\left\{\omega^{\prime}\right\}+\sum_{f \in F} Y_{f}$ with, for some $\lambda>0,\left(\omega^{\prime}-\omega\right) \leq \lambda \sum_{h \in H_{2}} \omega_{h}$.

As previously, a by-product of Proposition 5.3 is the following Lindahl-Foley equilibrium existence theorem:

Theorem 5.6. Assume that the dual pair $\left\langle L, L^{\prime}\right\rangle$ satisfies $\mathbf{S A}$. Under the assumptions A1-A8, and $\mathbf{I} \mathbf{R}^{\prime}$, the economy $\mathcal{E}$ has a Lindahl-Foley equilibrium $\left(\left(\left(\bar{x}_{h}\right)_{h \in H}, \bar{G}\right),\left(\bar{y}_{f}, \bar{y}_{f}^{g}\right)_{f \in F},\left(\bar{p},\left(\bar{p}_{h}^{g}\right)_{h \in H}\right)\right)$ with a private goods price vector $\bar{p} \in L^{\prime}$ satisfying $\bar{p} \cdot \omega>0$ and positive personalized price vectors for public goods, $\bar{p}_{h}^{g} \in \mathbb{R}_{+}^{K}, h \in H$, not all equal to zero.

\footnotetext{
${ }^{6}$ See Definition 5.3.6 of Florenzano (2003).

${ }^{7}$ See Definition 5.3.7 of Florenzano (2003).
} 


\section{REFERENCES}

ALIPRANTIS, C. D., D. J. BROWN, and O. BURKINSHAW (1987) Edgeworth equilibria in production economies, J. Econ. Theory 43, 252-290.

ALIPRANTIS, C. D., D. J. BROWN, and O. BURKINSHAW (1989) Existence and optimality of competitive equilibria, Berlin, Heidelberg and New York: Springer-Verlag.

ALLOUCH, N., and M. FLORENZANO (2004) Edgeworth and Walras equilibria of an arbitrage-free exchange economy, Econ. Theory 23, 353-370.

ARROW, K. J., and F. H. HAHN (1971) General Competitive Analysis, San Francisco: Holden-Day.

CONLEY, J. P. (1994) Convergence theorems on the core of a public goods economy:Sufficient conditions, $J$. Econ. Theory 62, 161-185.

DE SIMONE, A., and M. G. GRAZIANO (2004) The pure theory of public goods: the case of many commodities, J. Math. Econ. 40, 847-868.

DIAMANTARAS, D., and R. P. GILLES (1996) The pure theory of public goods: efficiency, decentralization and the core, Int. Econ. Rev. 37, 851-860.

FLORENZANO, M. (1990), Edgeworth equilibria, fuzzy core and equilibria of a production economy without ordered preferences, J. Math. Anal. Appl. 153, 18-36.

FLORENZANO, M. (2003) General Equilibrium Analysis: Existence and Optimality Properties of Equilibria, Boston/Dordrecht/London: Kluwer Academic Publishers.

FOLEY, D. K. (1970) Lindahl's solution and the core of an economy with public goods, Econometrica 38, $66-72$.

MAS-COLELL, A. (1980) Efficiency and decentralization in the pure theory of public goods, Quart. J. Econ. $94(4), 625-641$.

MAS-COLELL, A., and S. F. RICHARD (1991) A new approach to the existence of equilibria in vector lattices, J. Econ. Theory 53,1-11.

MAS-COLELL, A., and J. SILVESTRE (1989) Cost share equilibria: A Lindahlian approach, J. Econ. Theory 47, 239-256.

del MERCATO, E. L. (2004) Edgeworth equilibria with private provision of public good, in: Three market imperfections in the general equilibrium model, $\mathrm{PhD}$ thesis, Università degli Studi di Pisa.

MILLERON, J.-C. (1972) Theory of value with public goods: a survey article, J. Econ. Theory 5, 419-477.

SCARF, H. (1967) The core of a $n$ person game, Econometrica 35 (1967), 50-69.

TOURKY, R. (1998) A new approach to the limit theorem on the core of an economy in vector lattices, $J$. Econ. Theory 78, 321-328.

TOURKY, R. (1999) The limit theorem on the core of a production economy in vector lattices with unordered preferences, Econ. Theory 14, 219-226.

VASIL'EV, V. A. (1996) On Edgeworth equilibria for some types of nonclassical markets, Siberian Advances in Mathematics 6 N3, 1-55, Translated from Trudy Inst. Mat. Sobolev 28 (1994), 3-52.

VASIL'EV, V. A., S. WEBER, and H. WIESMETH (1995) Core equivalence with congested public goods, Econ. Theory 6, 373-387.

VILLANACCI, A., and U. ZENGINOBUZ (2001) Existence and regularity of equilibria in a general equilibrium model with private provision of a public good, Research Papers ISS/EC 2001-06, Bog̃aziçi Üniversitesi. 
VILLANACCI, A., and U. ZENGINOBUZ (2003) Private provision of a public good in a general equilibrium model, Research Papers, Bog̃aziçi Üniversitesi.

WEBER, S., and H. WIESMETH (1991) The equivalence of core and cost share equilibria in an economy with a public good, J. Econ. Theory 54 (1991), 180-197. 